\title{
Neutral Sphingomyelinase Inhibition Alleviates LPS-Induced Microglia Activation and Neuroinflammation after Experimental Traumatic Brain Injury
}

\author{
Asit Kumar, ${ }^{1}$ Rebecca J. Henry, Bogdan A. Stoica, David J. Loane, Gelareh Abulwerdi, \\ Shahnawaz A. Bhat, and Alan I. Faden \\ Department of Anesthesiology and Shock, Trauma and Anesthesiology Research (STAR) Center, University of Maryland School \\ of Medicine, Baltimore, Maryland
}

Received September 26, 2018; accepted December 14, 2018

\begin{abstract}
Neuroinflammation is one of the key secondary injury mechanisms triggered by traumatic brain injury (TBI). Microglial activation, a hallmark of brain neuroinflammation, plays a critical role in regulating immune responses after $\mathrm{TBI}$ and contributes to progressive neurodegeneration and neurologic deficits following brain trauma. Here we evaluated the role of neutral sphingomyelinase (nSMase) in microglial activation by examining the effects of the nSMase inhibitors altenusin and GW4869 in vitro (using BV2 microglia cells and primary microglia), as well as in a controlled cortical injury (CCI) model in adult male C57BL/6 mice. Pretreatment of altenusin or GW4869 prior to lipopolysaccharide (LPS) stimulation for 4 or 24 hours, significantly downregulated gene expression of the
\end{abstract}

pro-inflammatory mediators TNF- $\alpha, \mathrm{IL}-1 \beta$, IL-6, iNOS, and CCL2 in microglia and reduced the release of nitric oxide and TNF- $\alpha$. These nSMase inhibitors also attenuated the release of microparticles and phosphorylation of p38 MAPK and ERK1/2. In addition, altenusin pretreatment also reduced the gene expression of multiple inflammatory markers associated with microglial activation after experimental TBI, including TNF- $\alpha$, $\mathrm{IL}-1 \beta$, IL-6, iNOS, CCL2, CD68, NOX2, and $\mathrm{p} 22^{\text {phox }}$. Overall, our data demonstrate that nSMase inhibitors attenuate multiple inflammatory pathways associated with microglial activation in vitro and after experimental TBI. Thus, nSMase inhibitors may represent promising therapeutics agents targeting neuroinflammation.

\section{Introduction}

Recent clinical and experimental studies show that traumatic brain injury (TBI) initiates a sustained neuroinflammatory response with microglial activation that contributes to posttraumatic neurodegeneration and chronic neurologic deficits (Loane and Byrnes, 2010; Loane et al., 2014a). Such neurotoxic microglial activation is associated with both phenotypic and genotypic changes (Loane and Kumar, 2016). The latter include activation of inflammatory cytokines, chemokines, and microRNAs (miRs) (Perry et al., 2010; Prinz and Priller, 2014). Activated microglia also release extracellular vesicles (EVs),

This work was supported by the National Institutes of Health [Grant Number R01NS037313 (A.I.F.), R01NS082308 (D.J.L.), and R01NS096002 (B.A.S.)]

${ }^{1}$ Current affiliation: Department of Neurology, Richard T Johnson Division of Neuroimmunology and Neurological Infections, Johns Hopkins University School of Medicine, Baltimore, Maryland.

https://doi.org/10.1124/jpet.118.253955. including microparticles (MP; also called microvesicles) and exosomes containing pro-inflammatory molecules, which can further enhance and potentially propagate the inflammatory response after TBI (Hazelton et al., 2018; Paolicelli et al., 2018). Several in vitro and in vivo models, including lipopolysaccharide (LPS)-treated primary microglia, cell lines (e.g., BV2 microglia), and LPS-challenged mice have been used to mimic such neurotoxic microglial activation (Loane et al., 2009; Mao et al., 2012; Fenn et al., 2014; Yuan et al., 2015; Hung et al., 2017). The LPS model stimulates microglial activation pro-inflammatory phenotypic changes, and it has also been used in EVs studies whereby MP released from activated microglia are enriched in pro-inflammatory mediators such as interleukin-1 $\beta$ (IL-1 $\beta$ ) (Kumar et al., 2017; Yang et al., 2018). Experimental neuroprotection strategies for TBI have included modulation of upstream activation mechanisms using NADPH-oxidase (NOX2) inhibitors or mGluR5 agonists (Loane et al., 2013; Kumar et al., 2016a,b), as well as strategies serving to inhibit the release of specific inflammatory

ABBREVIATIONS: AD, Alzheimer's disease; Arg-1, arginase 1; CCI, controlled cortical injury; CCL2, C-C motif chemokine ligand 2; D68, cluster of differentiation 68; ERK, extracellular signal-regulated kinase; EV, extracellular vesicles; $1 \kappa \mathrm{B} \alpha$, nuclear factor of kappa light polypeptide gene enhancer in B-cells inhibitor, alpha; IL-1 $\beta$, interleukin-1 $\beta$; IL-6, interleukin 6; IL-4ra, IL-4 receptor subunit alpha; JNK, c-Jun N-terminal kinase; LPS, lipopolysaccharide; MAPK, mitogen-activated protein kinase; miR, microRNA; MP, microparticles; Mrc1/CD206, mannose receptor C-type 1/cluster of differentiation 206; MTT, tetrazolium salt 3-(4,5-dimethylthiazol-2-yl)-2,5-diphenyltetrazolium bromide; NF- $\kappa$ B, nuclear factor kappa-lightchain-enhancer of activated B cells; Nos2/iNOS, nitric oxide synthase 2/inducible nitric oxide synthase; NOX2, NADPH oxidase 2; nSMase, neutral sphingomyelinase; TBI, traumatic brain injury; TBS-T, Tris-buffered saline containing $0.1 \%$ Tween 20 ; TNF- $\alpha$, tumor necrosis factor-alpha; Ym1/Chil3, Ym1/chitinase-like 3. 
factors such as pro-inflammatory cytokines (Kumar et al., $2016 \mathrm{~b})$. We recently showed in a murine experimental TBI model that neutralization of EVs using a novel surfactant polyethylene glycol telomere $\mathrm{B}$ can serve to reduce the release of pro-inflammatory factors (Kumar et al., 2017); this treatment was also found to be neuroprotective in a porcine model of TBI (Bohman et al., 2016).

A number of studies have also begun to examine the effects of nSMase inhibitors, such as altenusin and GW4869, on brain immune cell function and as potential anti-inflammatory agents (Iguchi et al., 2016; Chua et al., 2017; Dickens et al., 2017; Huang et al., 2018; Sobue et al., 2018). The nSMases are a family of sphingomyelin phosphodiesterase enzymes that catalyze hydrolysis of sphingomyelin, a major component of eukaryotic cell membrane, to produce phosphocholine and ceramide (Wu et al., 2010; Figuera-Losada et al., 2015). Regulation of innate immune responses mediated through nSMase inhibition might provide beneficial effects for several neurodegenerative diseases (Guo et al., 2015; Dinkins et al., 2016; Bilousova et al., 2018). Prior studies demonstrate that nSMase inhibitors can limit neuroinflammation and neuronal cell death (Brann et al., 2002). Thus, such drugs can protect neurons, astrocytes, and oligodendrocytes against ceramideinduced cell death produced by pro-inflammatory molecules (tumor necrosis factor- $\alpha$; TNF- $\alpha$ ), $\beta$-amyloid, and cerebral ischemia (Luberto et al., 2002; Lee et al., 2004; Zeng et al., 2005; Martinez et al., 2012; Gu et al., 2013). Recent studies indicate that myeloid cells can release EVs/MP that spread inflammatory signals both in vitro and in vivo to alter neuronal functions (Harrison-Brown et al., 2016; Nigro et al., 2016; Beneventano et al., 2017; Kumar et al., 2017). Importantly, EV levels are significantly increased following TBI in humans and animal models, as well as in chronic neurodegenerative and autoimmune disorders such as Alzheimer's disease $(\mathrm{AD})$ and multiple sclerosis, supporting the concept that spreading inflammation via EVs release may play a role in these neuropathologies (Taylor and Gercel-Taylor, 2014; Xiao et al., 2017; Pieragostino et al., 2018). Thus, nSMase inhibitors have emerged as new pharmacological agents for preventing release of EVs and thus can modulate inflammation and oxidative stress.

In the present study, we investigated the therapeutic potential of the nSMase inhibitors altenusin and GW4869 in BV2 murine microglial cell line and primary microglia in vitro, as well as in the mice subjected to controlled cortical impact (CCI), a well-characterized experimental TBI model. More specifically, we examined their ability to modulate LPS-induced microglial activation, as well as release of proinflammatory molecules and EVs in vitro, and on markers of secondary neuroinflammation following TBI in mice. In addition, we evaluated the potential underlying signal transduction mechanisms involved.

\section{Materials and Methods}

Animals. Studies were performed using 10- to 12 -week-old C57BL/6 male mice (22-26 g wt; Taconic Biosciences, Germantown, NY). Mice were housed in the Animal Care Facility at the University of Maryland School of Medicine under standard laboratory conditions, maintained on 12 -hour light/dark cycle with temperature of $24^{\circ} \mathrm{C}$, with ad libitum access to food and water. Mice were acclimatized in the animal surgery room half an hour before the surgery. All surgical procedures were performed in accordance with protocols approved by the Institutional Animal Care and Use Committee (IACUC) at the University of Maryland School of Medicine.

Controlled Cortical Impact. Brain injury in mice was induced using our custom-designed CCI injury device, consisting of a microprocessor-controlled pneumatic impactor with a $3.5 \mathrm{~mm}$ diameter tip as described previously (Kabadi et al., 2012). Briefly, mice were anesthetized in gas chamber containing evaporated mixture of gases $70 \% \mathrm{~N}_{2} \mathrm{O}$ and $30 \% \mathrm{O}_{2}$ along with isoflurane (induction at $4 \%$ and maintenance at $2 \%$ ) and directed through a nose mask. Depth of anesthesia was assessed, before initiation of the surgical procedure, by monitoring respiration rate and pedal withdrawal reflexes. Animals were placed on a heated pad to maintain a body temperature of $37^{\circ} \mathrm{C}$ under the anesthesia. The head was mounted in a stereotaxic frame and a $10-\mathrm{mm}$ midline incision was made over the skull. After reflecting the skin and fascia, a 5-mm craniotomy was made on the central aspect of the left parietal bone. The impounder tip of the injury device was positioned to the surface of the exposed dura after extending to its full stroke distance $(44 \mathrm{~mm})$ and reset to impact the cortical surface. Moderate injury was induced using an impactor velocity of $6 \mathrm{~m} / \mathrm{s}$ and deformation depth of $2 \mathrm{~mm}$. After performing the CCI injury, the incision was closed with interrupted 6-0 silk sutures. After anesthesia withdrawal, the animal was placed into a heated cage for at least $45 \mathrm{~min}$ postinjury to maintain the normal body temperature. All animals were monitored carefully for at least 4 hours after surgery. Sham animals underwent the same procedure as injured mice except for craniotomy and cortical impact.

In Vivo Drug Treatments. At 30 minutes postinjury injured, mice received a single intraperitoneal injection of altenusin (Millipore Sigma, St. Louis, MO) at 2 or $10 \mathrm{mg} / \mathrm{kg}$ in saline + dimethyl sulfoxide (DMSO; Millipore Sigma) or equal volume of vehicle (saline + DMSO). Drug dosages were partly based upon prior in vivo studies for altenusin in mice (Chua et al., 2017). At 24 hour postinjury, mice were humanely euthanized and brain tissues were rapidly dissected and stored at $-80^{\circ} \mathrm{C}$ following transcardial perfusion with ice-cold sterile phosphate-buffered saline (PBS).

BV2 Cell Culture. BV2 murine microglial cells were cultured in Dulbecco's modified Eagle's medium (DMEM; Life Technologies, Carlsbad, CA) supplemented with $10 \%$ fetal calf serum (Life Technologies) and $1 \%$ penicillin and streptomycin $(40 \mathrm{U} / \mathrm{ml}$ and $40 \mu \mathrm{g} / \mathrm{ml}$, respectively; Millipore Sigma) at $37^{\circ} \mathrm{C}$ with $5 \% \mathrm{CO}_{2}$. Cells were split 1: 5 until their confluency using $0.05 \%$ Trypsin-EDTA (Life Technologies) solution in phosphate buffered saline (PBS). For activation of BV-2 microglia, lipopolysaccharide (LPS from Escherichia coli; $20 \mathrm{ng} / \mathrm{ml}$; Millipore Sigma) was used. BV2 microglia were seeded at a density of either $3 \times 10^{5}$ cells/well ( 6 -well plate), $1.5 \times 10^{5}$ cells/well (12-well plate), $0.75 \times 10^{5}$ cells/well ( 24 -well plate), or 20,000 cells/well (96-well plate). Cells were incubated with or without various concentration of altenusin $(10-100 \mu \mathrm{M})$ or GW4869 $(5-10 \mu \mathrm{M}$; Millipore Sigma) followed by LPS stimulation $(20 \mathrm{ng} / \mathrm{ml})$ for either 4 or 24 hours.

Primary Microglia Cultures. Primary microglia cultures were prepared from cerebral cortices of postnatal day P1-3 SpragueDawley rats as previously described (Olajide et al., 2014; Singh et al., 2014). In brief, brains were carefully taken, and cerebral cortices were collected and freed from meninges in Hanks' balanced salt solution (without calcium, magnesium, and phenol red; Life Technologies). Forebrains were minced and gently dissociated by repeated pipetting in DMEM/F-12 medium (Life Technologies) and filtered by passing through $70-\mu \mathrm{m}$ cell strainer (Millipore Sigma). Cells were collected by centrifugation $\left(1000 \mathrm{~g}, 10\right.$ minutes at $\left.4^{\circ} \mathrm{C}\right)$ and resuspended in DMEM/F-12 containing $10 \%$ fetal calf serum (Life Technologies) and $1 \%$ penicillin and streptomycin $(40 \mathrm{U} / \mathrm{ml}$ and $40 \mu \mathrm{g} / \mathrm{ml}$, respectively) and cultured on Poly-D-lysine coated $75 \mathrm{~cm}^{2}$ cell culture flask (Millipore Sigma) in $5 \% \mathrm{CO}_{2}$ at $37^{\circ} \mathrm{C}$. After $12-14$ days in culture, floating microglia were harvested from mixed glia (astrocytemicroglia) cultures and reseeded into cell culture plates at the density of either $0.75 \times 10^{5}$ cells/well ( 24 -well plate) or $1.5 \times 10^{5}$ cells/well (12-well plate). On the next day, nonadherent cells were removed by 
changing the media, and after 1 hour cells were used for experiments. Cells were incubated with altenusin $(10-50 \mu \mathrm{M})$ followed by LPS stimulation ( $20 \mathrm{ng} / \mathrm{ml}$ ) for either 4 or 24 hours.

Cell Viability Assay. Cell viability was determined using a tetrazolium salt 3-(4,5-dimethylthiazol-2-yl)-2,5-diphenyltetrazolium bromide (MTT; Millipore Sigma) colorimetric assay (Mosmann, 1983). BV2 microglia cells were incubated in 96-well plates in DMEM containing $10 \%$ fetal calf serum and $1 \%$ penicillin and streptomycin (40 U/ml and $40 \mu \mathrm{g} / \mathrm{ml}$, respectively) containing various concentrations of altenusin $(1-100 \mu \mathrm{M})$ and GW4869 $(1-20 \mu \mathrm{M})$ for 24 hours. Ten microliters of MTT at a final concentration of $0.5 \mathrm{mg} / \mathrm{ml}$ were added to each well. After 3-hour incubation in $5 \% \mathrm{CO}_{2}$ at $37^{\circ} \mathrm{C}$, media was discarded and formazan crystals were dissolved by adding $100 \mu \mathrm{l}$ of DMSO to each well. The absorbance was measured at $540 \mathrm{~nm}$ using absorbance microplate reader (Biotek, Winooski, VT) and is directly proportional to cell viability. Cell viability was expressed as a percentage of surviving cells compared with the nonstimulated control cells.

mRNA Real-Time PCR. RNA was isolated using Direct-zol RNA mini prep kit (ZYMO Research, Irvine, CA). For cDNA synthesis, total RNA was reverse transcribed using High-Capacity cDNA Reverse Transcription Kit (ThermoFisher Scientific, Waltham, MA) as per manufacturer's instructions. In brief, each $20 \mu \mathrm{l}$ of reverse transcription (RT) reaction consisted of $2 \mu \mathrm{l}$ of $10 \times$ RT buffer, $0.8 \mu \mathrm{l}$ of $25 \times \mathrm{dNTP} \operatorname{mix}(100 \mathrm{mM}), 2.0 \mu \mathrm{l}$ of $10 \times \mathrm{RT}$ random primers, $1.0 \mu \mathrm{l}$ of MultiScribe reverse transcriptase, $4.2 \mu \mathrm{l}$ of nuclease-free water, and $10 \mu \mathrm{l}$ of RNA sample. Thermal cycling conditions used for reverse transcription are 10 minutes at $25^{\circ} \mathrm{C}$, 120 minutes at $37^{\circ} \mathrm{C}$, and finally 5 minutes at $85^{\circ} \mathrm{C}$ followed by stop at $4^{\circ} \mathrm{C}$. The synthesized cDNA was the template for the realtime PCR amplification that was carried out either by ABI 7900 HT or Quant Studio 5 real-time PCR System (ThermoFisher Scientific), using TaqMan Universal Master Mix II, no UNG (ThermoFisher Scientific) as per the company's protocol. Reaction conditions were 10 minutes at $95^{\circ} \mathrm{C}$, followed by 40 cycles of 15 seconds at $95^{\circ} \mathrm{C}, 60$ seconds at $60^{\circ} \mathrm{C}$, followed by the final plate read. The following primers were used in this study: Mm00443258_m1 TNF- $\alpha$ (mouse), Rn01525859_g1 TNF- $\alpha$ (rat), Mm00446190_m1 IL-6 (mouse), Rn01410330_m1 IL-6 (rat), Mm01336189_m1 IL-1 $\beta$ (mouse), Rn00580432_m1 IL-1 $\beta$ (rat), Mm00440502_m1 Nos2/iNOS (mouse), Rn00561646_m1 Nos2/iNOS (rat), Mm00441242_m1 CCL2 (mouse), Rn00580555_m1 CCL2 (rat), Mm01288386_m1 IL-10 (mouse), Mm99999915_g1, GAPDH (mouse), Rn01775763_g1 GAPDH (rat), Mm03047343_m1 CD68 (mouse), Mm01287743_m1 CYBB/NOX2 (mouse), Mm00514478_m1 CYBA/p22 $2^{\text {phox }}$ (mouse), Mm01275139_m1 IL4ra (mouse), Mm01329362_m1 Mrc1/CD206 (mouse), Mm00475988_m1 Arg-1 (mouse), Mm00657889_mH Ym1/Chil3 (mouse). GAPDH served as an internal control for sample normalization and the comparative cycle threshold method $\left(2^{-\Delta \Delta \mathrm{Ct}}\right)$ was used for data quantification as described previously (Livak and Schmittgen, 2001).

microRNA Real-Time PCR. Following RNA isolation using Direct-zol RNA mini prep kit (ZYMO Research), miRNAs were reverse-transcribed by using TaqMan microRNA reverse transcription kit (ThermoFisher Scientific) according to manufacturer's protocol. In brief, the master mix of $7 \mu \mathrm{l}$ contained $1.5 \mu \mathrm{l}$ of reverse transcription buffer $(10 \times), 0.15 \mu \mathrm{l}$ of dNTPs $(100 \mathrm{mM}$; with deoxythymidine triphosphate), $1 \mu \mathrm{l}$ of MultiScribe Reverse Transcriptase (50 U/ $\mu \mathrm{l}$ ), $0.19 \mu \mathrm{l}$ of RNase inhibitor $(20 \mathrm{U} / \mu \mathrm{l})$, and $4.16 \mu \mathrm{l}$ nuclease-free water. Each $15 \mu \mathrm{l}$ of RT reaction consisted of $7 \mu \mathrm{l}$ of master mix, $3 \mu \mathrm{l}$ of RT primer $(5 \times)$, and $5 \mu \mathrm{l}$ of RNA sample $(10 \mathrm{ng})$. Thermal cycling conditions used for reverse transcription are 30 minutes at $16^{\circ} \mathrm{C}$, 30 minutes at $42^{\circ} \mathrm{C}$, and finally 5 minutes at $85^{\circ} \mathrm{C}$ followed by stop at $4^{\circ} \mathrm{C}$. For real-time PCR amplification of mature miRNA, TaqMan Universal PCR master mix II $(2 \times)$ with no UNG and TaqMan Small RNA assays $(20 \times)$ were used according to manufacturer's protocol (mmu480953_mir miR-155, mmu478399_mir miR-146a, 001973 U6 snRNA). In brief, the reaction setup for real-time PCR of $20 \mu \mathrm{l}$ contained $10 \mu \mathrm{l}$ of TaqMan Universal PCR master mix II $(2 \times), 1 \mu \mathrm{l}$ of TaqMan Small RNA assay $(20 \times), 1.33 \mu \mathrm{l}$ of template cDNA, and 7.67 of $\mu \mathrm{l}$ nuclease-free water. The cycling condition for real-time PCR involved 40 cycles started with PCR initial enzyme activation step for 10 minutes at $95^{\circ} \mathrm{C}$ and then 15 seconds at $95^{\circ} \mathrm{C}$ and 60 seconds at $60^{\circ} \mathrm{C}$. The real-time qPCR results were normalized to RNU6 (Life Technologies) and quantified using comparative $\mathrm{Ct}$ method $2^{-\Delta \Delta \mathrm{Ct}}$ (Livak and Schmittgen, 2001). PCR reactions were carried out either by ABI 7900HT or Quant Studio 5 real-time PCR System (ThermoFisher Scientific).

Microparticle Analysis by Flow Cytometry. Microparticles (MP), a special class of extracellular vesicles released into BV2 microglial media were characterized using a MACSQuant flow cytometer (Miltenyi Biotec, Auburn, CA) as described previously (Kumar et al., 2017). For MP analysis, fetal calf serum (Life Technologies) was subjected to 18 hours centrifugation at $100,000 \mathrm{~g}$. DMEM media was filtered using $0.22-\mu \mathrm{m}$ filter (Millipore). Cells were pretreated with altenusin and GW4869 for 30 minutes followed by LPS stimulation for 24 hours. To induce the MP shedding, cells were conditioned with $100 \mu \mathrm{M}$ of BzATP for 30 minutes. At the end of the experiment, cell supernatants were used to collect total MP that were purified by using ultracentrifugation at the speed of $300 \mathrm{~g}$ for 10 minutes, $2100 \mathrm{~g}$ for 10 minutes followed by $100,000 \mathrm{~g}$ for 1 hour at $4^{\circ} \mathrm{C}$ as previously described (Poncelet et al., 2015; Tian et al., 2015; Kumar et al., 2017) with minor modification. To characterize the size of MP, MACSQuant was first calibrated with calibration beads (Miltenyi Biotec), and forward and side scatters were set at logarithmic gain. Photomultiplier tube voltage and triggers were optimized to detect submicron-sized particles. Microbead standards of various sizes 300 nm (Sigma, St. Louis, MO; LB3), 1090 (BCP-10-5; Spherotech), and $3000 \mathrm{~nm}$ (BP-30-5; Spherotech, Lake Forest, IL) were used to set the initial parameters in the flow cytometer. MP were distinguished from larger (apoptotic body; $>1000 \mathrm{~nm}$ ) and smaller (exosomes; $<100 \mathrm{~nm}$ ) vesicles based on size (SSC), and their phenotype was confirmed using the APC-conjugated Annexin V (Catalog No. 550474; BD Bioscience, San Jose, CA). All reagents and solutions used for MP analysis were sterile and filtered ( 0.1 or $0.22 \mu \mathrm{m}$ filter; Millipore) before use.

Western Blotting. To generate whole cell extracts, cells were washed with cold PBS and lysed in the radioimmunoprecipitation assay buffer (RIPA buffer; Teknova, Hollister, CA), with 3\% phosphatase (Phosphatase Inhibitor Cocktail 2 and 3; Millipore Sigma) and protease inhibitor cocktail (Millipore Sigma). Protein concentration of the samples was measured using the bicinchoninic acid protein assay kit (ThermoFisher Scientific) according to the manufacturer's instructions. For Western blotting, $15 \mu \mathrm{g}$ of total protein from each sample was subjected to 5\%-20\% gradient gels for sodium dodecyl sulfatepolyacrylamide gel electrophoresis. Proteins were transferred onto nitrocellulose membranes and blocked in 5\% BSA in Tris-buffered saline containing $0.1 \%$ Tween 20 (TBS-T). After blocking, membranes were incubated with primary antibodies, including phospho-p38 MAPK (1:1000; Cell Signaling Technology, Danvers, MA), phosphoERK1/2 (1:1000; Cell Signaling Technology), phospho-JNK (1:1000; Cell Signaling Technology), anti-I $\kappa$ B- $\alpha$ (1:1000; Cell Signaling Technology), and rabbit anti-actin (1:5000; Cell Signaling Technology). Primary antibodies were diluted in TBS-T and 5\% BSA. Membranes were incubated with the primary antibody overnight at $4^{\circ} \mathrm{C}$ followed by incubation in appropriate horseradish peroxidase-conjugated secondary antibodies (Jackson Immuno Research Laboratories, West Grove, PA) for 1 hour at room temperature. After extensive washing (3 times for 15 minutes each in TBS-T), proteins were visualized using Super Signal West Dura Extended Duration Substrate (ThermoFisher Scientific). Chemiluminescence was captured using ChemiDoc TM XRS+ System (Bio-Rad, Hercules, CA). Densitometry analyses of the proteins were performed using ImageJ software (NIH, Bethesda, MD), and $\beta$-actin was used to confirm equal sample loading and normalization of the data.

Nitrite Release. Nitrite levels in cell culture supernatant were measured using a Griess reagent kit (ThermoFisher Scientific) 
according to manufacturer's instruction. Absorbance was measured at $548 \mathrm{~nm}$ using the Synergy HT multi-mode microplate reader (Biotek) and normalized with the reference sample. Amount of nitrite (expressed in micromoles) released by microglia cells in each sample was calculated by plotting standard curve.

Determination of TNF- $\alpha$ Release from LPS-Activated Microglia. Levels of TNF- $\alpha$ released in BV2 and primary rat microglia cell culture supernatant were measured using mouse and rat ELISA kit from R\&D Systems, Minneapolis, MN; and BD Biosciences, respectively, as per manufacturer's instructions. Briefly, standards or samples were added to antibody-coated 96-well plates and incubated for 2 hours at RT. After washing the plates with wash buffer, samples were incubated with detection antibody for another 2 hours at RT. Plates were washed and incubated in horseradish peroxidase-conjugated streptavidin for 20 minutes at RT in dark. Substrate solution was added and plate was left for incubation 30 minutes in the dark. After the incubation, stop solution was added and absorbance was measured at $450 \mathrm{~nm}$ using a Synergy HT Multi-Mode Microplate Reader (Biotek). A standard curve was used to calculate the levels of TNF- $\alpha$ release and expressed as picograms of cytokine/milliliters.

Statistical Analysis. Statistical analyses were performed using GraphPad Prism software (GraphPad Software Inc., San Diego, CA). Values of all experiments are represented as mean \pm S.E.M. of at least three independent experiments. Values were compared using one-way analysis of variance with Tukey's post hoc correction (multiple comparisons). The level of significance was set at $* P<0.05,{ }^{* *} P<0.01,{ }^{*} * * P<0.001$.

\section{Results}

Effects of Altenusin and GW4869 on the Microglial Cell Viability. To determine the cytotoxic potential of altenusin (Fig. 1A) and GW4869 (Fig. 1B), the viability of BV2 microglia was evaluated using an MTT assay. Treatment with altenusin (ranging from 1 to $100 \mu \mathrm{M}$ ) prior to LPS stimulation $(20 \mathrm{ng} / \mathrm{ml})$ did not adversely affect BV2 microglia viability when compared with control or unstimulated cells (Fig. 1C). Similarly, pretreatment of GW4869 (ranging from 1 to $10 \mu \mathrm{M}$ ) did not affect microglial cell viability (Fig. 1D); however, $20 \mu \mathrm{M}$ GW4869 with $(P<0.05)$ and without LPS $(P<0.01)$ significantly decreased cell viability, indicating GW4869 cytotoxicity $>10 \mu \mathrm{M}$.

Altenusin and GW4869 Attenuate LPS-Induced Activation of BV2 Microglia. To investigate whether altenusin and GW4869 exerts anti-inflammatory effects, BV2 microglia were preincubated with altenusin and GW4869 for 30 minutes and then stimulated with or without LPS. We evaluated gene expression levels of key pro-inflammatory cytokines (TNF- $\alpha$, IL-1 $\beta$, and IL-6), inducible form of nitric oxide synthase (iNOS), chemokine (CCL2), and the anti-inflammatory cytokine (IL-10). Based on time-course analysis (data not shown), we identified the time point for mRNA analysis to be 4 hours post-LPS stimulation when pro-inflammatory mRNAs were robustly induced. LPS stimulation of BV2 microglia significantly increased the expression of TNF- $\alpha$ (LPS vs. control, $P<0.001$ ), IL- $1 \beta$ (LPS vs. control, $P<0.001$ ), IL-6 (LPS vs. control, $P<0.001$ ), iNOS (LPS vs. control, $P<0.001$ ), and CCL2 (LPS vs. control, $P<0.001$ ) (Fig. 2, A-E). Pretreatment of altenusin significantly reduced expression of TNF- $\alpha$ (Fig. 2A) and IL-6 (Fig. 2B) at 75 (TNF $\alpha, P<0.001$; IL- $6, P<0.001$ ) and $100 \mu \mathrm{M}$ (TNF- $\alpha, P<0.001$; IL-6, $P<0.001$ ) compared with LPS alone. Altenusin also significantly decreased expression of IL-1 $\beta$ (Fig. 2C), iNOS (Fig. 2D), and CCL2 (Fig. 2E), starting at $50 \mu \mathrm{M}$ (LPS vs. LPS + altenusin; IL- $1 \beta, P<0.001$; iNOS, $P<0.001$; CCL2, $P<0.01$ ). Similarly, pretreatment of GW4869 for 30 minutes significantly reduced gene expression of TNF- $\alpha$ (5-10 $\mu \mathrm{M}, P<0.001$; Fig. 2G), IL-6 (5-10 $\mu \mathrm{M}$, $P<0.001$; Fig. 2H), IL-1 $\beta$ (5-10 $\mu \mathrm{M}, P<0.001$; Fig. 2I), iNOS $(10 \mu \mathrm{M}, P<0.05$, Fig. 2J), CCL2 (5-10 $\mu \mathrm{M}, P<0.001$; Fig. 2K) following LPS stimulation. Altenusin and GW4869 did not significantly increase IL-10 gene expression following LPS stimulation (Fig. 2, F and L).

With regard to protein markers, peak expression of TNF- $\alpha$ and nitric oxide production in BV2 and primary microglia is at 24 hours following LPS stimulation (Loane et al., 2014;
A<smiles>COc1cc(O)c(C(=O)O)c(-c2cc(O)c(O)cc2C)c1</smiles>

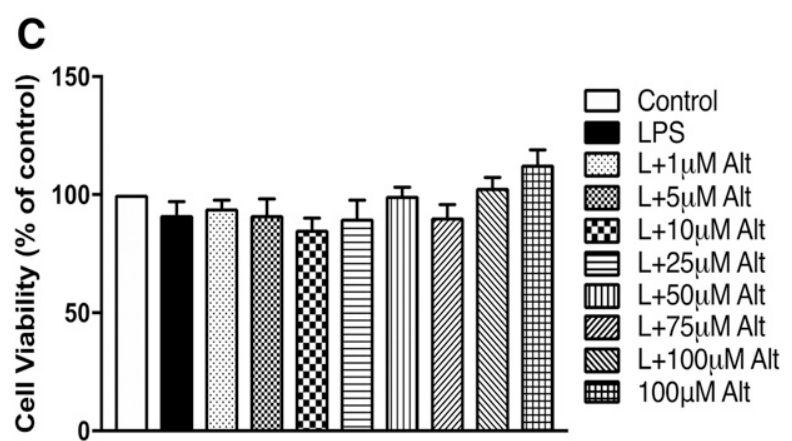

B
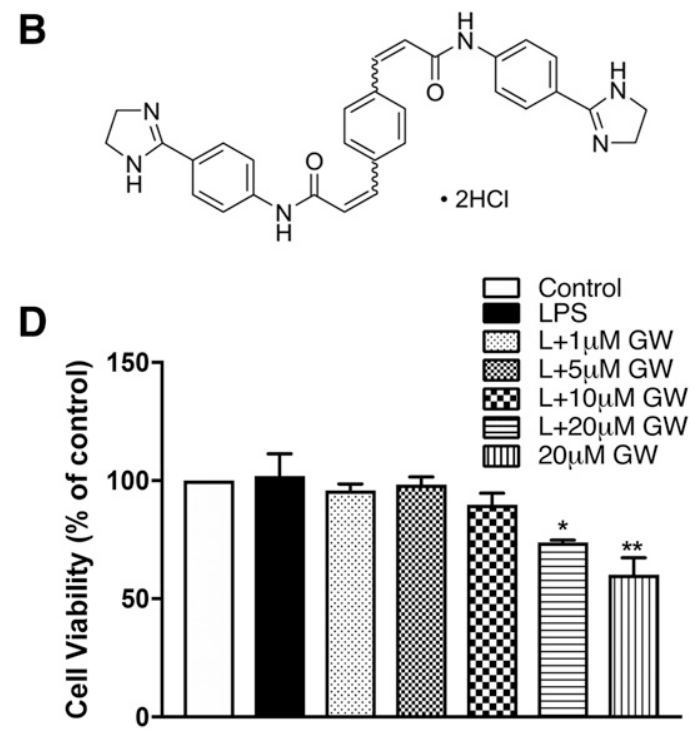

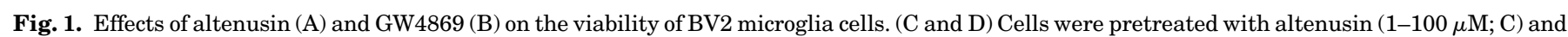

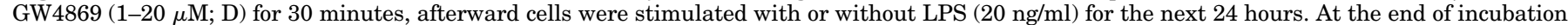

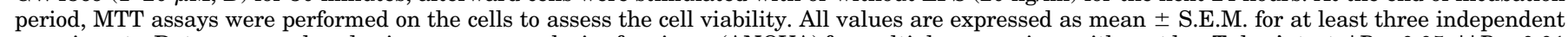

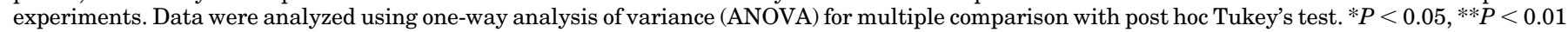
compared with control cells. 

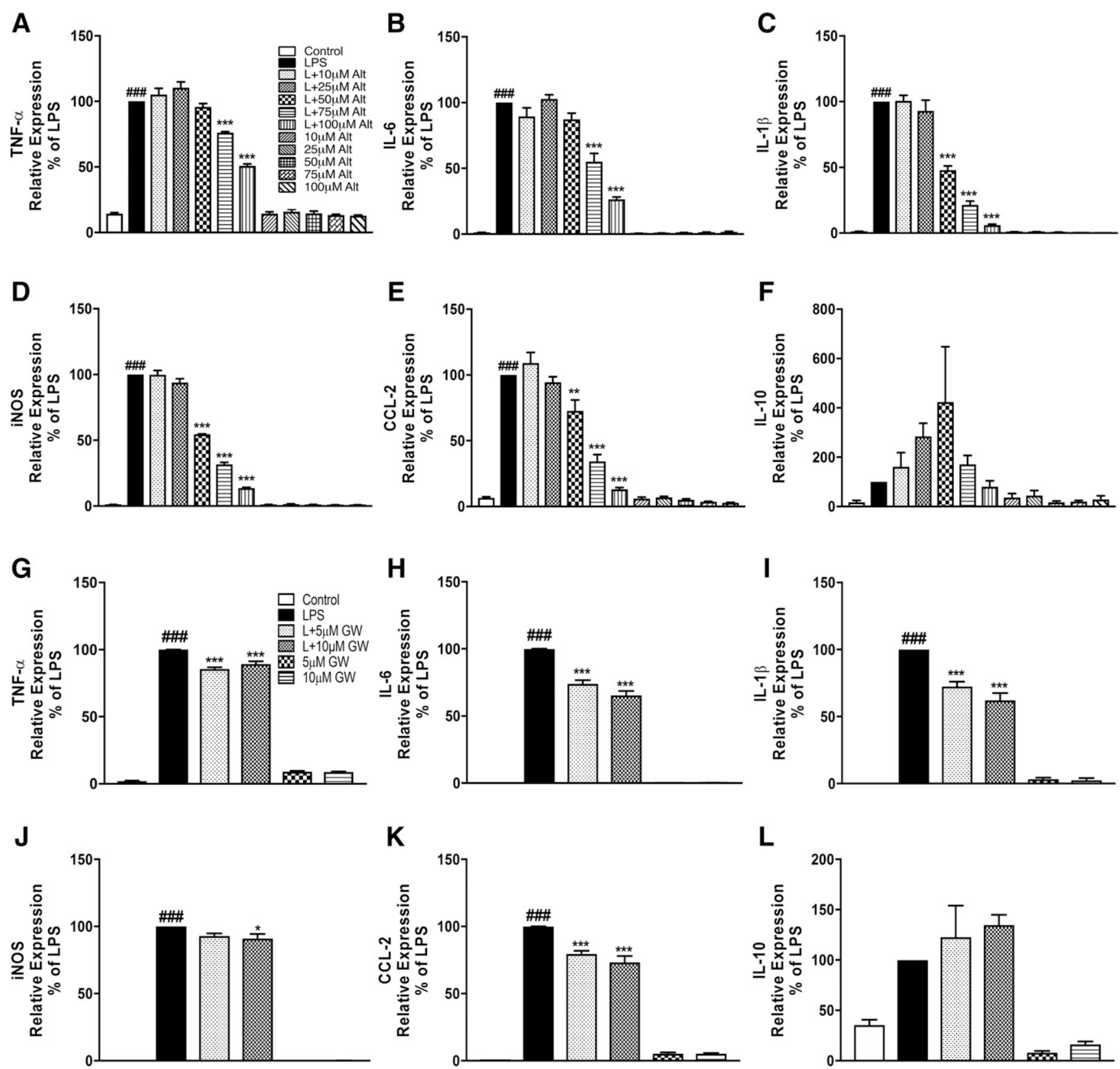

Fig. 2. Effects of altenusin and GW4869 on the expression of pro-inflammatory mediators in BV2 microglia (A-L). Cells were pretreated with altenusin (10-100 $\mu \mathrm{M}$ ) for 30 minutes, afterward cells were stimulated with or without LPS ( $20 \mathrm{ng} / \mathrm{ml}$ ) for 4 hours for studying gene expression of TNF- $\alpha$ (A), IL-6 (B), IL-1 $\beta$ (C), iNOS (D), CCL2 (E), IL-10 (F). Similarly, for analyzing effect of GW4869 on gene expression of inflammatory mediators, cells were pretreated with GW4869 $(5-10 \mu \mathrm{M})$ for 30 minute followed by stimulation with or without LPS (20 ng/ml) for the next 4 hour for analyzing gene expression of TNF- $\alpha(\mathrm{G})$, IL-6 (H), IL-1 $\beta$ (I), iNOS (J), CCL2 (K), IL-10 (L). Data are presented as percentage control of LPS. Statistical analyses were carried out by using one-way ANOVA with post hoc Tukey's test (multiple comparisons). Results are expressed as mean \pm S.E.M. of at least three independent experiments. $* P<0.05,{ }^{* * P}<0.01$, ${ }^{* * *} P<0.001$ in comparison with LPS; ${ }^{\# \#} P<0.001$ in comparison with control.

Stoica et al., 2014; Kumar et al., 2017). As predicted, we observed a significant increase in the nitrite levels and TNF- $\alpha$ protein in the supernatant of BV2 stimulated with LPS at 24 hours compared with control treated cells (Fig. 3). Altenusin pretreatment significantly decreased nitrite production in a dosedependent manner, starting at $25 \mu \mathrm{M}$ (LPS vs. LPS + altenusin; $P<0.001$; Fig. 3A). Similarly, GW4869 pretreatment significantly reduced nitrite release following LPS stimulation, starting at $5 \mu \mathrm{M}$ (LPS vs. LPS + GW4869; $P<0.001$; Fig. 3B). Altenusin and GW4869 treatment did not significantly change the nitrite levels when added to BV2 microglia in the absence of LPS. Pretreatment of altenusin significantly decreased TNF- $\alpha$ protein levels following LPS stimulation, starting at $75 \mu \mathrm{M}$ (LPS vs. LPS + altenusin; $P<0.001$; Fig. 3C), whereas TNF- $\alpha$ levels were significantly decreased following GW4869 treatment at $10 \mu \mathrm{M}$ (LPS vs. LPS + GW4869; $P<0.05$; Fig. 3D).

Altenusin Attenuate LPS-Induced Activation of Primary Microglia. To confirm the data obtained from BV2 microglial cells, we also tested the anti-inflammatory properties of altenusin in primary rat microglia. In response to LPS stimulation, we observed a robust increase in the mRNA levels of TNF- $\alpha$ (LPS vs. control, $P<0.001$ ), IL-6 (LPS vs. control, 

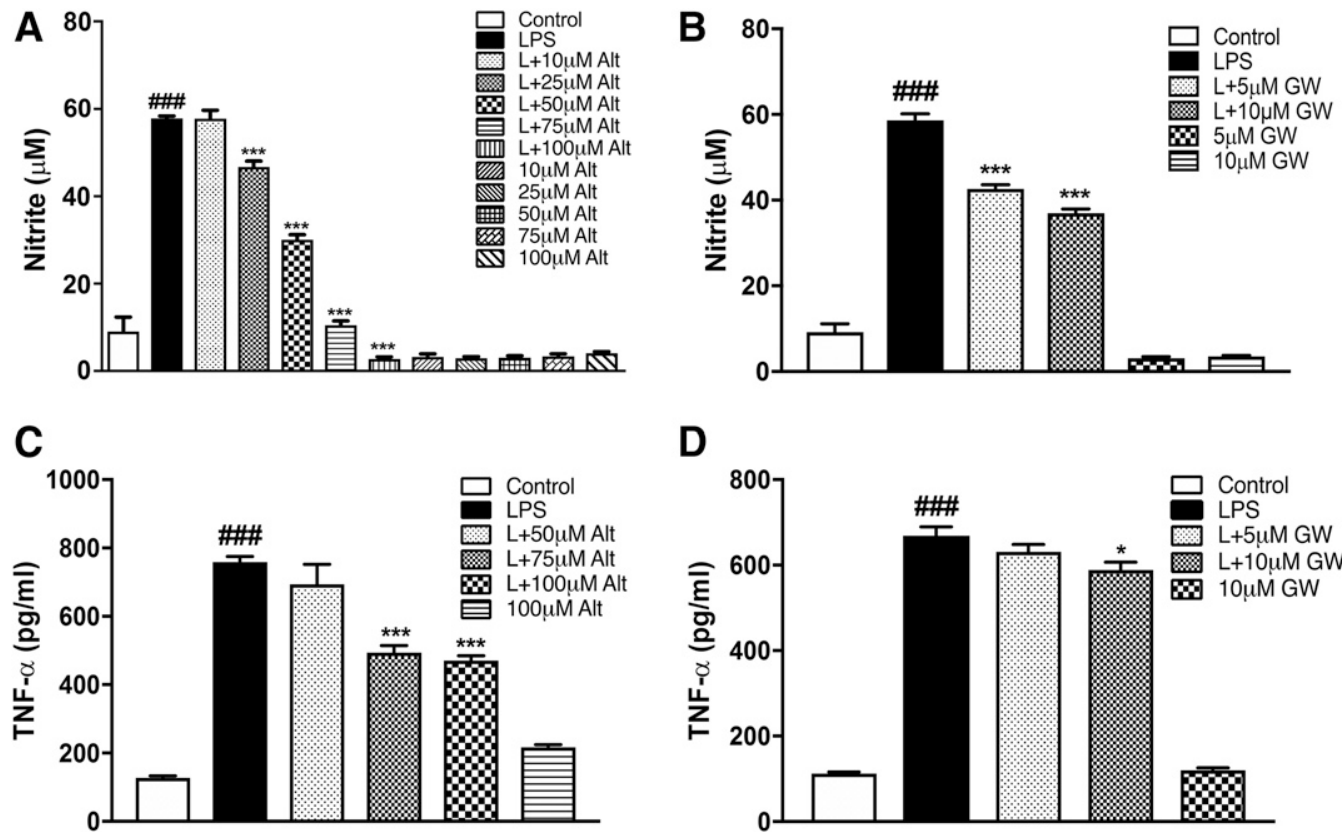

Fig. 3. Effects of altenusin and GW4869 on the release of nitrite (A and B) and TNF- $\alpha$ (C and D) in BV2 microglia cells. For nitrite estimation, cells were pretreated with altenusin [10-100 $\mu \mathrm{M}(\mathrm{A})]$ and GW4869 [5-10 $\mu \mathrm{M}(\mathrm{B})]$. For TNF- $\alpha$ ELISA, cells were pretreated with altenusin [50-100 $\mu \mathrm{M}(\mathrm{C})]$ and GW4869 [5-10 $\mu \mathrm{M}$ (D)]. Cells were pretreated for 30 minutes followed by stimulation with or without LPS ( $20 \mathrm{ng} / \mathrm{ml})$ for the next $24 \mathrm{hours}$. At the end of incubation, cell supernatants were collected, centrifuged, and levels of nitrite, and TNF- $\alpha$ was quantified by using Griess reagent assay and mouse specific ELISA assay, respectively. Statistical analyses were carried out by using one-way ANOVA with post hoc Tukey's test (multiple comparisons). Results are expressed as mean \pm S.E.M. of at least three independent experiments. ${ }^{*} P<0.05, * * P<0.01, * * * P<0.001$ in comparison with LPS; ${ }^{\# \# \# ~} P<0.001$ in comparison with control.

$P<0.001$ ), IL- $1 \beta$ (LPS vs. control, $P<0.01$ ), iNOS (LPS vs. control, $P<0.001$ ), and CCL2 (LPS vs. control, $P<0.01$; Fig. 4). Pretreatment with altenusin resulted in a significant downregulation of TNF- $\alpha$ (Fig. 4A), IL-6 (Fig. 4B), and iNOS (Fig. 4D) starting at $10 \mu \mathrm{M}(\mathrm{TNF} \alpha, P<0.001$; IL-6, $P<0.001$; iNOS, $P<0.001$ ), whereas IL-1 $\beta$ (Fig. 4C) and CCL2 (Fig. 4E) expression were significantly decreased starting at 25 (IL- $1 \beta$, $P<0.05$; CCL2, $P<0.01$ ) and $50 \mu \mathrm{M}$ (IL- $1 \beta, P<0.01$; CCL2, $P<0.01$ ) of altenusin. Next, we investigated the LPS-induced release of nitrite and TNF- $\alpha$ in primary rat microglia (Fig. 5, A and $B)$. LPS stimulation resulted in a significant increase in the release of nitrite (Fig. 5A) and TNF- $\alpha$ protein (Fig. 5B). Pretreatment with altenusin significantly reduced nitrite levels starting at $10 \mu \mathrm{M}$ (LPS vs. LPS + altenusin; $P<0.001$; Fig. 5A), whereas levels of TNF- $\alpha$ protein was significantly reduced starting at $25 \mu \mathrm{M}$ (LPS vs. LPS + altenusin; $P<0.001$; Fig. 5B).

Altenusin and GW4869 Attenuate LPS-Induced Elevation of Pro-inflammatory miR-155. We assessed changes in pro-inflammatory miR-155 and miR-146 levels in BV2 microglia pretreated with altenusin and GW4869 and stimulated with LPS (Fig. 5, C and D). Altenusin or GW4869 treatment prior to LPS stimulation significantly decreased miR-155 expression at $100 \mu \mathrm{M}$ altenusin $(P<0.01$ vs. LPS $)$ and at $10 \mu \mathrm{M}$ GW4869 $(P<0.01$ vs. LPS) (Fig. 5C), respectively, but these inhibitors had no significant effects on LPS-induced miR-146 expression (Fig. 5D).

Effects of Altenusin and GW4869 on the Microparticle Release Induced by Combined Treatment with LPS and BzATP. Next, we investigated if altenusin and GW4869 had any effect on the MP release in activated microglia (Fig. 6). $\mathrm{P} 2 \mathrm{X} 7$ triggers MP shedding in the microglia, which can be activated by agonists such as ATP or BzATP (synthetic analog of ATP) (Bianco et al., 2005, 2009). Therefore, BV2 microglia were pretreated with altenusin and GW4869 for 30 minutes and then stimulated with or without LPS for 24 hours followed by an additional BzATP stimulation for 30 minutes to induce MP shedding (Kumar et al., 2017). MP were quantified by flow cytometry using annexin $\mathrm{V}$, which binds the externalized phosphatidylserine present on the MP surface. Apoptotic bodies $(>1000 \mathrm{~nm})$ and exosomes $(<100 \mathrm{~nm})$ were excluded by gating analysis, and MP ranging in size between 300 and $1000 \mathrm{~nm}$ were analyzed (Fig. 6A). LPS/BzATP significantly induced the shedding of annexin $\mathrm{V}$ positive MP compared with MP levels in control BV2 microglia $(P<0.001$; Fig. 6B). Interestingly, we found that altenusin (50 and $100 \mu \mathrm{M})$ and GW4869 (5 and $10 \mu \mathrm{M})$ significantly decreased the microparticle count $(P<0.001)$ in the activated BV2 microglia.

Altenusin Inhibits the Pro-inflammatory Pathways p38 MAPK and ERK1/2. Mitogen-activated protein kinase (MAPK) pathways are implicated in several cellular processes, including neuroinflammation (Kaminska, 2005; Kaminska et al., 2009). To further investigate the mechanism by which altenusin modulates cytokines production, we assessed altenusin effects on the activation of various components of MAPK in LPS-activated BV2 microglia (Fig. 7A). LPS treatment of microglia for 30 minutes led to the phosphorylation, and thus activation of p38 MAPK $(P<0.001)$, ERK1/2 $(P<0.05)$, and JNK $(P<0.001)$ (Fig. 7, B-D). Notably, pretreatment of altenusin at $100 \mu \mathrm{M}$ significantly reduces phosphorylation of p38 $(P<0.05$ vs. LPS; Fig. 7B). Similarly, there was a significant reduction in the phosphorylation of ERK1/2 by altenusin $(P<0.05$ vs. LPS; Fig. 7C). In contrast, altenusin failed to reduce LPS-stimulated phosphorylation of JNK (Fig. 7D) or degradation of $\mathrm{I} \kappa \mathrm{B} \alpha$ (Fig. 7E). 

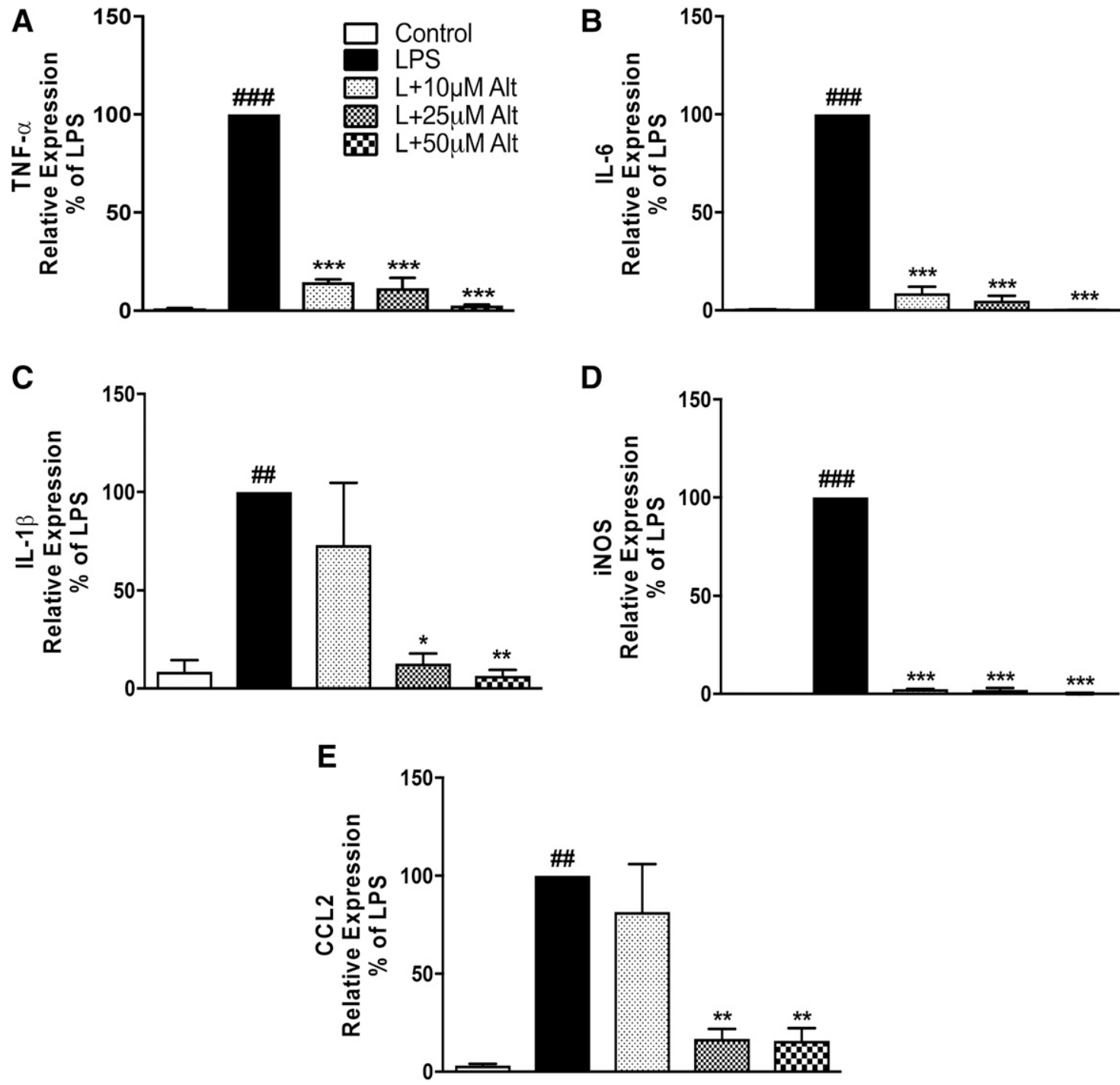

Fig. 4. Effects of altenusin on the expression of pro-inflammatory mediators in primary rat microglia (A-E). Cells were pretreated with altenusin (10-50 $\mu \mathrm{M})$ for 30 minutes; afterward cells were stimulated with LPS $(20 \mathrm{ng} / \mathrm{ml})$ for 4 hours for studying gene expression of TNF- $\alpha$ (A), IL-6 (B), IL-1 $\beta$ (C), iNOS (D), CCL2 (E). Data are presented as percentage control of LPS. Statistical analyses were carried out by using one-way ANOVA with post hoc Tukey's test (multiple comparisons). Results are expressed as mean \pm S.E.M. of at least three independent experiments. ${ }^{*} P<0.05$; $* * P<0.01 ; * * * P<0.001$ in comparison with LPS; ${ }^{\#} P<0.01 ;{ }^{\# \#} P<0.001$ in comparison with control.

Systemic Treatment of Altenusin Attenuates Acute Neuroinflammation following Experimental Traumatic Brain Injury in Mice. We then investigated whether altenusin has similar anti-inflammatory properties in vivo. We used a well-established model of CCI in adult male C57BL/6 mice to induce a cortical focal contusion injury and examined whether the increases in gene expression of proinflammatory cytokines and chemokines were ameliorated by altenusin treatment. Two and ten milligrams per kilogram of altenusin was administered systemically (intraperitoneally) to moderatelevel CCI mice starting at 30 minutes postinjury (Fig. 8A). Sham-treated and CCI mice were euthanized 24 hours later, and cortical tissue was collected for mRNA analysis of $\mathrm{TNF} \alpha$, IL-6, IL-1 $\beta$, iNOS, CCL2, CD68, NOX2, and p22 ${ }^{\text {phox }}$. Following CCI, there was a robust increase in mRNA for proinflammatory mediators TNF $\alpha$, IL- 6 , IL- $1 \beta$, iNOS, and CCL2 $(P<0.001$ vs. sham; Fig. $8, \mathrm{~B}-\mathrm{F})$. Altenusin $(10 \mathrm{mg} / \mathrm{kg})$ treatment significantly reduced the expression levels of TNF- $\alpha(P<0.01$; Fig. 8B), IL-6 $(P<0.05$; Fig. 8 C $)$, IL-1 $\beta$
$(P<0.05$; Fig. 8D), iNOS $(P<0.05$; Fig. $8 \mathrm{E})$, and CCL2 $(P<0.01$; Fig. 8F) compared with vehicle-treated CCI group. We also evaluated the expression of CD68, a marker of activated and phagocytic microglia (Song et al., 2011; Fu et al., 2014; Walker and Lue, 2015). CD68 expression was significantly increased in the vehicle-treated CCI group $(P<0.05$ vs. sham; Fig. $8 \mathrm{G})$, and its expression was significantly reduced with altenusin $(10 \mathrm{mg} / \mathrm{kg})$ treatment $(P<0.05$ vs. vehicle-treated CCI). NOX2 has been implicated in microglial-mediated neurotoxicity in TBI (Loane et al., 2014; Kumar et al., 2016), so we analyzed the gene expression of NOX2 and $\mathrm{p} 22^{\text {phox }}$ in the injured cortex. There was a significant increase in the expression of NOX2 and p22 ${ }^{\text {phox }}$ mRNA expression with $\mathrm{CCI}(P<0.001$ vs. sham; Fig. 8, $\mathrm{H}$ and $\mathrm{I})$, and altenusin treatment $(10 \mathrm{mg} / \mathrm{kg})$ significantly reduced both subunit expression $(P<0.05$ vs. vehicle-treated $\mathrm{CCI}$.

Finally, to investigate whether altenusin has modulatory effects on anti-inflammatory and proresolution immune 
A

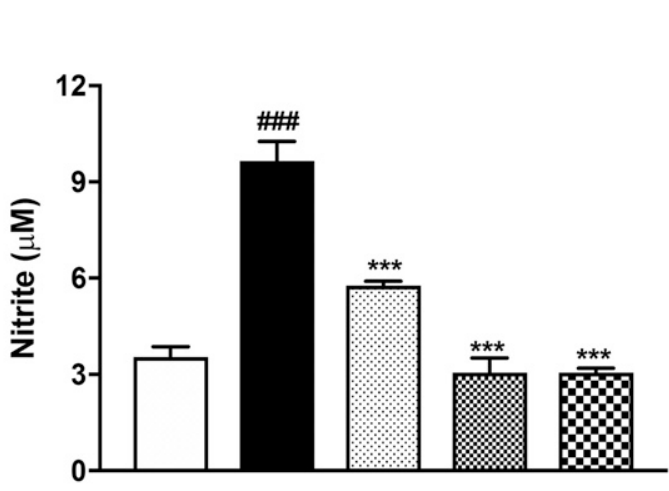

C

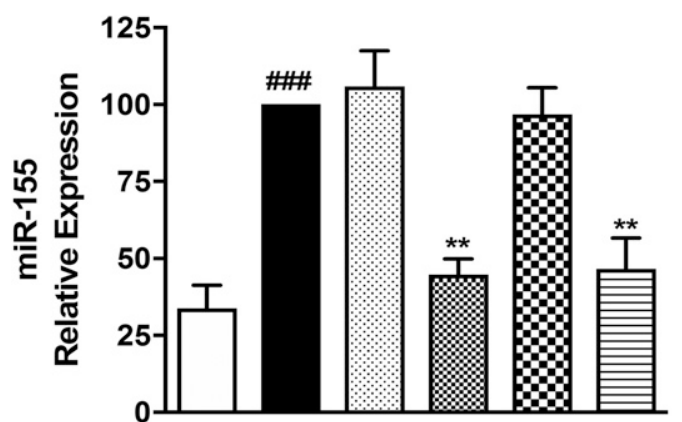

B

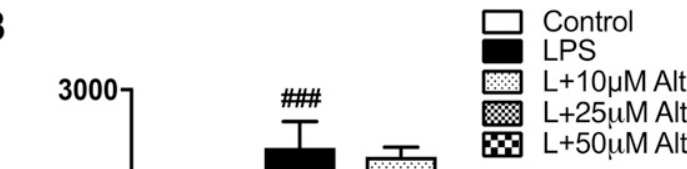

D

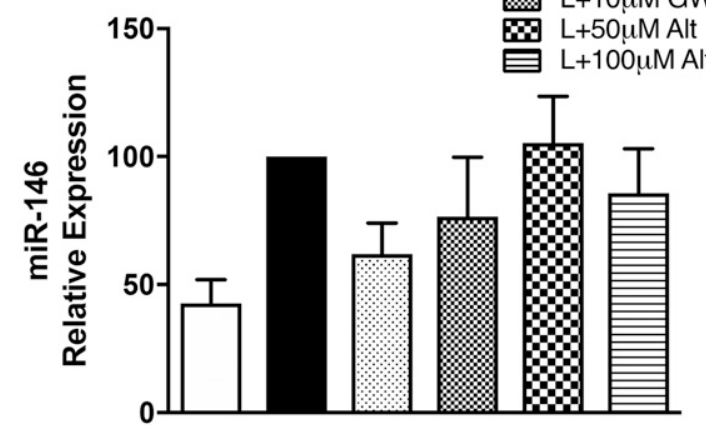

Fig. 5. Effects of altenusin on the release of nitrite and TNF- $\alpha$ in primary rat microglia (A and B). For estimation of nitrite and TNF- $\alpha$ release, cells were pretreated with altenusin $(10-50 \mu \mathrm{M})$ for 30 minutes followed by stimulation with LPS $(20 \mathrm{ng} / \mathrm{ml})$ for the next 24 hours. At the end of incubation, cell supernatants were collected and centrifuged and levels of nitrite (A), and TNF- $\alpha$ (B) was quantified by using Griess reagent assay and rat specific ELISA assay, respectively. For miRNA expression of miR-155 (C) and miR-146 (D), cells were pretreated with altenusin $(50-100 \mu \mathrm{M})$ and GW4869 (5-10 $\mu \mathrm{M})$ for 30 minutes, followed by LPS stimulation for 4 hours. Altenusin $(100 \mu \mathrm{M})$ and GW4869 $(10 \mu \mathrm{M})$ significantly decreased the miR-155 (C), but not miR146 (D), expression in LPS-stimulated BV2 cells. Statistical analyses were carried out by using one-way ANOVA with post hoc Tukey's test (multiple comparisons). Results are expressed as means \pm S.E. of at least three independent experiments. $* * P<0.01 ; * * * P<0.001$ in comparison with LPS;

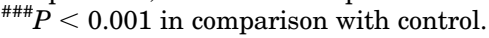

responses, we assessed anti-inflammatory and alternative activation microglial markers (IL-10, IL-4ra, Arg-1, Mrc1/CD206, and Ym1/Chil3). CCI induced significant increase in IL-10, IL-4ra, Arg-1 mRNA expression in the injured cortex $(P<$ 0.05-0.001 vs. sham; Fig. 9, A, B, and D), as well as increased Mrc1/CD206 and Ym1/Chil3 expression that failed to reach statistical significance (Fig. 9, C and E). Post-injury treatment of altenusin at both doses ( 2 and $10 \mathrm{mg} / \mathrm{kg}$ ) did not increase expression of these anti-inflammatory and proresolving genes in the injured cortex beyond vehicle-treated CCI levels (Fig. 9).

\section{Discussion}

In the present study, we demonstrate the anti-inflammatory effects of nSMase inhibitors in activated microglia in vitro and in an experimental TBI model in mice. Altenusin and GW4869 significantly suppressed neuroinflammation, reducing the gene expression of proinflammatory cytokines (TNF $\alpha$, IL- $1 \beta$, IL-6), chemokines (CCL2), and iNOS, as well as microglia activation markers (CD68) and components of NADPH oxidase (NOX2, p22 ${ }^{\text {phox }}$ ). They also reduced the extracellular release of TNF- $\alpha$ and nitric oxide in activated BV2 cells and primary microglia. These inflammatory molecules are known to be important mediators of microglial activation and neuroinflammation associated with several neurologic conditions, including TBI (Hanisch, 2002; Woodcock and MorgantiKossmann, 2013; Thelin et al., 2017).

GW4869 is a selective, noncompetitive nSMase2 inhibitor that shows no inhibitory activity on acid sphingomyelinase (aSMase) (Luberto et al., 2002), whereas altenusin is a nonsteroidal fungal metabolite with broader nSMase inhibitor activity, known to target multiple isoforms of nSMase (Uchida et al., 1999; Dickens et al., 2017). In the current study, we demonstrated that both nSMase inhibitors attenuated LPS-induced microglial activation and the release of pro-inflammatory mediators in vitro, although altenusin had greater potency and less cytotoxicity than GW4869. Some prior studies have demonstrated therapeutic effects of GW4869 at $20 \mu \mathrm{M}$ in breast cancer cells, macrophages, and mesenchymal stem cells (Wu et al., 2005; Essandoh et al., 2015; Xiao et al., 2018); however, in our studies $20 \mu \mathrm{M}$ GW4869 significantly induced cytotoxicity, thereby negatively impacting microglial cell viability beginning at concentration of $>10 \mu \mathrm{M}$. The differences we identified in the GW4869 cytotoxicity profile compared with the abovementioned studies may be due to the different cell types examined (microglia vs. non-brain-derived cells). Collectively, our data suggest that a more general inhibition of nSMase activity may improve effectiveness. A limitation of pharmaceutical intervention approaches used to address potential mechanisms is that they may have off-target 
A
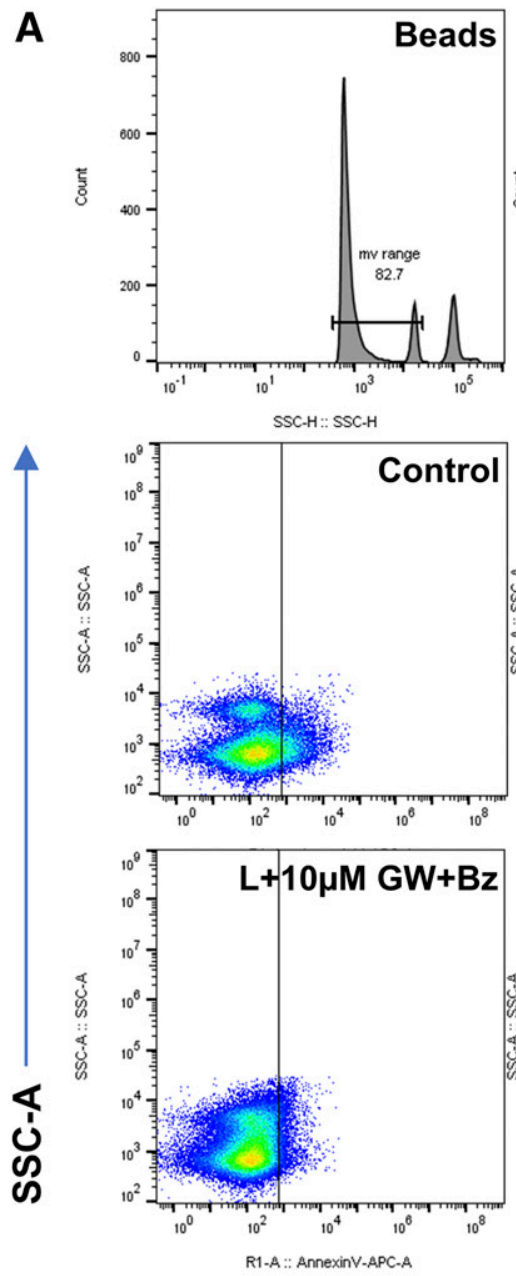
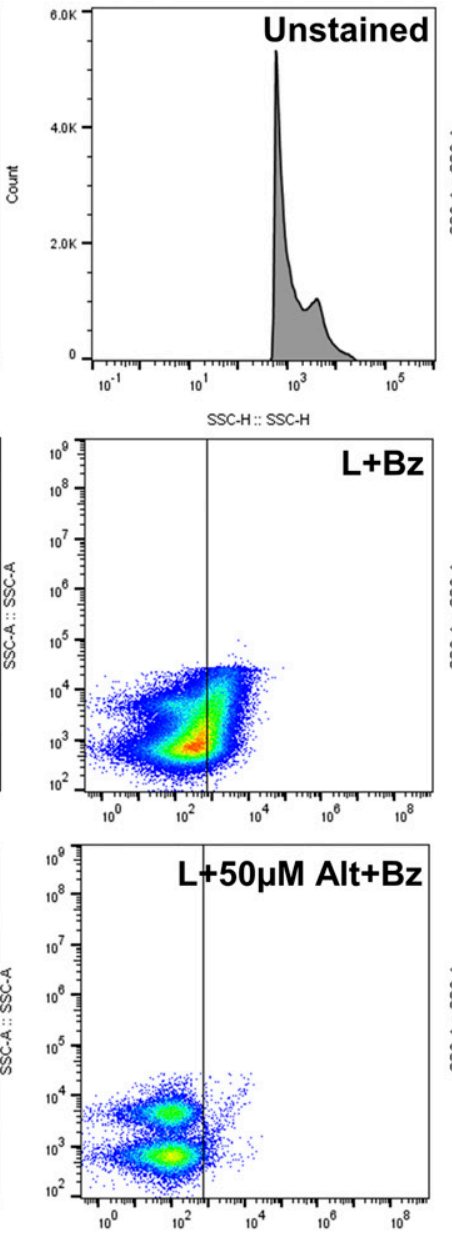

R1-A : AnnexinV-APC-A

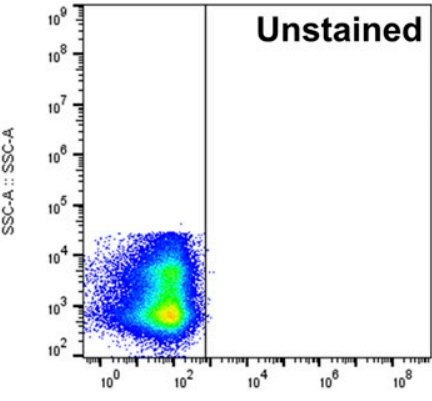

R1-A:: AnnexinY-APC.A
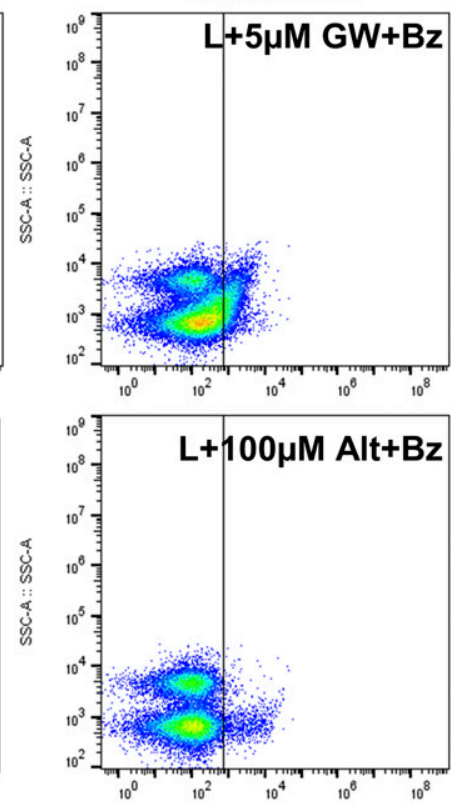

R1-A:: AnnexinV-APC.A

\section{AnnexinV-APC}

B

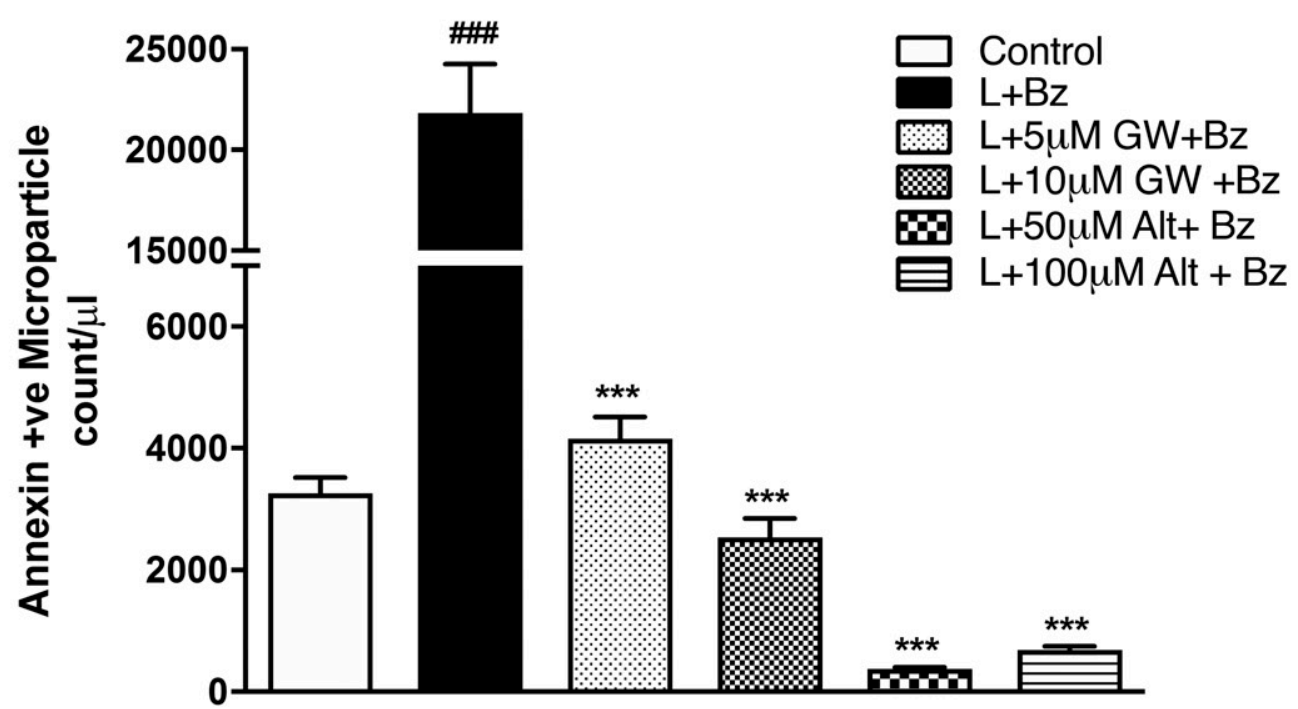

Fig. 6. Microglia-derived MP are decreased in the BV2 cell culture supernatant following treatment of altenusin and GW4869. BV2 microglial cells were pretreated with altenusin (50-100 $\mu \mathrm{M})$ and GW4869 (5-10 $\mu \mathrm{M})$ for 30 minutes followed by LPS (20 ng/ml) stimulation for $24 \mathrm{hours}$. Afterward cells were incubated with BzATP $(100 \mu \mathrm{M})$ for 30 minutes. (A) At the end of incubation, cell supernatants were collected, centrifuged, and release of MPs were quantified by flow cytometry. Flow cytometry analysis of enriched MP isolated from the supernatant using sequential centrifugation at $300 \mathrm{~g}$ for 10 minutes, $2100 \mathrm{~g}$ for 10 minutes followed by 100,000 $\mathrm{g}$ for 1 hour. Representation of gating strategy used to characterize MP/MV using 
activity. For example, altenusin has been shown to have inhibitory effects on a number of kinases, including Src kinase (Aly et al., 2008), and it is an agonist of the Farnesoid $\mathrm{X}$ receptor, a member of the nuclear receptor subfamily (Zheng et al., 2017).

Recent preclinical studies have implicated nSMases in neurodegenerative disorders and as regulators of neuroinflammation. A recent study in an animal model of $\mathrm{AD}$ suggested that nSMase2 may contribute to the progression of the disease and that nSMase2 loss of function improves neurocognitive function (Dinkins et al., 2016) and limits pathologic changes. Pharmacological inhibition of nSMases with altenusin also inhibits aggregation of tau protein in vitro (Chua et al., 2017). Gene expression of mitochondrial-associated sphingolipid-metabolizing enzymes was shown to increase significantly in the brain of TBI mice (Novgorodov et al., 2014). Another study reported the activation of the nSMase2/ceramide pathway in astrocytes, but not neurons, in the hippocampus after cerebral ischemia in rats (Gu et al., 2013). nSMases appear to regulate leukocyte migration to the brain following IL- $1 \beta$-induced brain injury, and their pharmacological inhibition by intrastriatal administration of altenusin significantly reduced glial cell activation and cytokine expression (Dickens et al., 2017). Furthermore, GW4869 significantly downregulates the gene expression of pro-inflammatory cytokines (TNF $\alpha$, IL- $1 \beta$, IL-6) in rat hippocampus after cerebral ischemia ( $\mathrm{Gu}$ et al., 2013). Notably, GW4869 suppressed the production of pro-inflammatory cytokines in LPS-stimulated RAW264.7 macrophages and in a sepsis-induced inflammatory model (Essandoh et al., 2015). Furthermore, mature dendritic cells, upon LPS stimulation, can produce pro-inflammatory cytokines, including TNF- $\alpha$ contained exosomes that are attenuated by GW4869 (Gao et al., 2016).

In previously published studies, we demonstrated that secondary neurodegeneration and chronic neurologic deficits following experimental TBI are driven by a pronounced proinflammatory and neurotoxic microglial activation that persists in injured cortex for days, weeks, or potentially months to years following the initial traumatic event (Byrnes et al., 2012; Loane et al., 2014a,b; Kumar et al., 2016a,b). We also showed that LPS stimulation of BV2 microglia and primary microglia represent excellent in vitro model that mimic the proinflammatory neuroinflammatory events initiated acutely in our TBI model (Loane et al., 2009, 2013). By using an LPS model of microglial activation in vitro, we demonstrate that both altenusin and GW4869 treatment attenuate the gene expression of TNF $\alpha$, IL-1 $\beta$, IL-6, iNOS, and CCL2. A previous study has shown that nSMase 2 is activated by TNF- $\alpha$ (Clarke et al., 2011). Thus, our data are consistent with others indicating that nSMase2 activation is an important step for the amplification (positive feedback) of the neuroinflammatory signaling program. We investigated the effects of nSMase inhibition on the gene expression of anti-inflammatory cytokine IL-10 in activated microglia. We found that although transcriptional levels of IL-10 increased somewhat following altenusin and GW4869 pretreatment, such changes did not reach statistical significance. These preliminary results indicate that nSMase inhibition produces robust anti-inflammatory response in microglia without upregulating inflammationresolving programs driven by IL-10. Further investigation into mechanisms by which nSMase inhibition regulates proand anti-inflammatory microglial activation phenotypes will be required to identify signal transduction pathways leading to beneficial inflammation-resolving responses in microglia.

Accumulating evidence supports the involvement of miRNAs as key regulators in the pathogenesis of various neurologic conditions, including neuroinflammation (Guedes et al., 2013), neurodegeneration (Sabirzhanov et al., 2018), autoimmune diseases (Ponomarev et al., 2011), and central nervous system injury (Sabirzhanov et al., 2014). miR-155 and miR-146 are two well-characterized pro-inflammatory miRs that are associated with microglial activation and regulate cytokine release, chemokine production, and oxidative stress (Cardoso et al., 2012; Saba et al., 2012, 2014; Guedes et al., 2014; Butovsky et al., 2015). Prior work has shown that miR-155 and miR-146 may be involved in modulation of microglial-mediated neuroinflammation by inducing proinflammatory cytokines in microglia (Jayadev et al., 2013; Yin et al., 2017) and neuronal cell death in various brain injury models (Caballero-Garrido et al., 2015; Harrison et al., 2016, 2017; Pena-Philippides et al., 2016). It has been demonstrated that miRNA-155 and -146a mediate cell-to-cell communication through exosomes/microvesicles (MV) and participate in target gene modulation in bone marrow-derived dendritic cells and cardiovascular disease (Montecalvo et al., 2012; Hulsmans and Holvoet, 2013). We recently showed that miR155 is significantly upregulated in cortex after experimental TBI and that central administration of miR-155 inhibitors (antagomirs) can reduce neuroinflammation and improve outcomes (Henry et al., 2018). In the present study, upregulation of miR-155 and miR-146 expression were observed in LPS-activated BV2 microglial cells. Following treatment with altenusin or GW4869, expression of miR-155 was substantially decreased, whereas no changes were observed in miR-146 expression, providing evidence that nSMase 2 acts upstream of the key pro-inflammatory miR-155.

We and others previously showed that microglia can release $\mathrm{EVs}$ that further activate the neighboring microglia and propagate the neuroinflammatory responses in the injured brain (Brites and Fernandes, 2015; Kumar et al., 2017; Paolicelli et al., 2018; Yang et al., 2018). The nSMase pathway is known to be involved in the biogenesis of EVs (Menck et al., 2017). Studies have shown that LPS-induced systemic inflammation causes the choroid plexus to secrete exosome and propagate a pro-inflammatory response in the brain and that these processes can be attenuated by GW4869 (Balusu et al., 2016). LPS also enhances exosome release from pulmonary artery smooth muscle cells, promoting cell proliferation and apoptosis resistance and contributing to the pathogenesis of pulmonary hypertension; GW4869 may attenuate pulmonary hypertension by inhibiting the exosome release (Zhao et al., 2017). Inhibition of nSMase with altenusin resulted in sharp

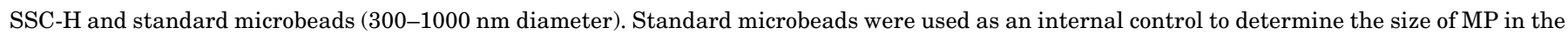

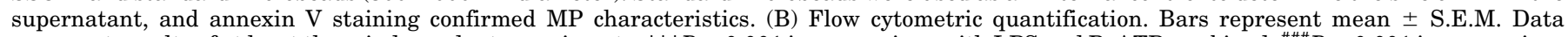

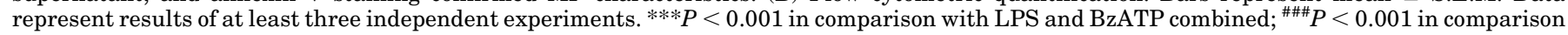
with control. 
A
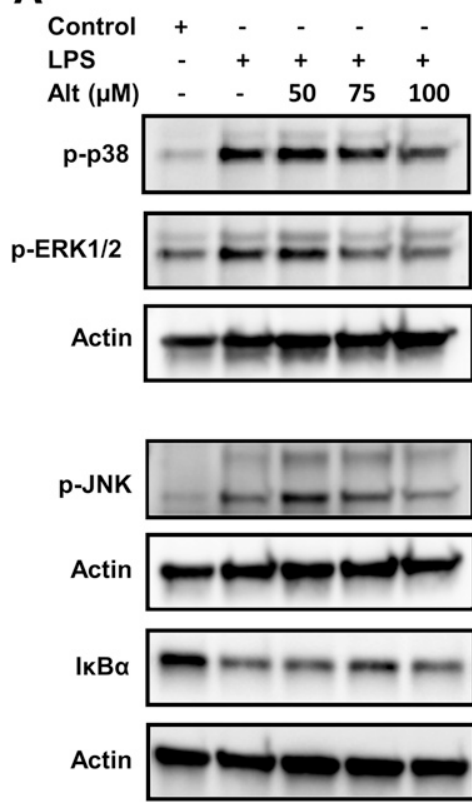

B

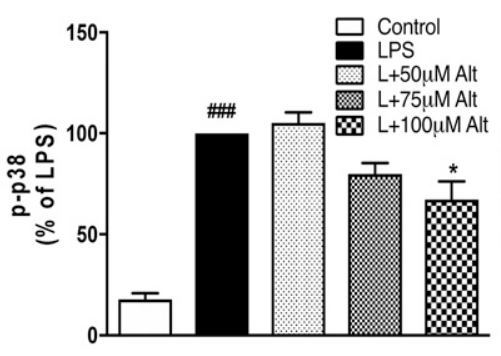

D

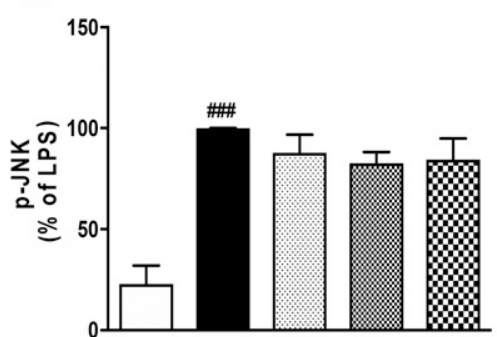

C

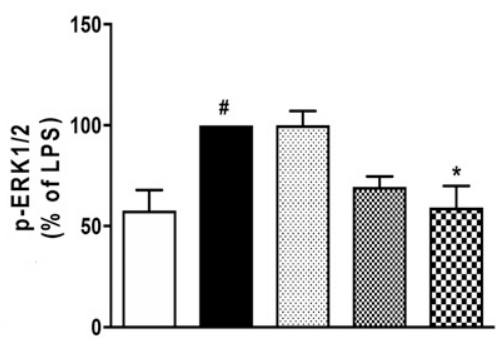

E

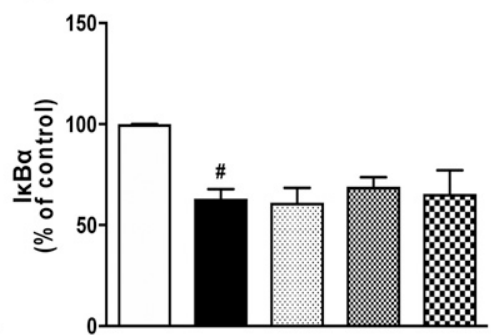

Fig. 7. Effects of altenusin on the phosphorylation of p38, ERK $1 / 2$, JNK, degradation of $\mathrm{I} \kappa \mathrm{B} \alpha$ induced by LPS. BV2 cells were pretreated with altenusin $(50-100 \mu \mathrm{M})$ for 30 minutes followed by stimulation with LPS $(20 \mathrm{ng} / \mathrm{ml})$ for 30 (for phospho-p38, -ERK1/2, and -JNK) and $15 \mathrm{minutes}($ for I $\kappa \mathrm{B} \alpha$ ). Whole cell lysates were used for Western blot analysis. (A) Representative blots and densitometric analysis (B-E) of p38 MAPK (B), ERK1/2 MAPK (C), JNK (D), and $\mathrm{I} \kappa \mathrm{B} \alpha(\mathrm{E})$, respectively. Statistical analyses were carried out by using one-way ANOVA with post hoc Tukey's multiple comparisons test. Results are expressed as means \pm S.E.M. of at least three independent experiments. ${ }^{*} P<0.05$, in comparison with LPS-activated cells; ${ }^{\#} P<0.05$, ${ }^{\# \# \#} P<0.001$ in comparison with control.

decline in the IL- $1 \beta$ induced EVs in vitro and in vivo (Dickens et al., 2017). The ATP receptor P2X7 and its agonists have been implicated in the shedding of IL- $1 \beta$ containing MP (Bianco et al., 2009; Li et al., 2017) and release of proinflammatory mediators during CNS inflammatory events (Hide et al., 2000; Shieh et al., 2014), and these mechanisms require acid sphingomyelinase (Bianco et al., 2009). Here we examine the effect on nSMase inhibition on microglial pro-inflammatory responses and how it relates to microglial-mediated MP release. Previously, we demonstrated that MP loaded with pro-inflammatory molecules ( $\mathrm{TNF} \alpha$, IL-1 $\beta$, miR-155) initially released by microglia immediately following brain trauma can seed microglial-mediated neuroinflammation that may contribute to progressive neurodegeneration in the injured brain (Kumar et al., 2017). In the present study, we examined the effects of nSMase inhibition on MP release from microglia as an outcome measure, because these drugs were previously found to modulate release of extracellular vesicles (Essandoh et al., 2015; Dickens et al., 2017). We determined that nSMase inhibitors reduced the release of MP following treatment with LPS and BzATP, with altenusin being more effective than GW4869. Thus our data suggest that nSMases may play an important role in EVs/MP shedding in microglial and associated inflammatory responses, but further in-depth investigations are needed to determine the mechanisms involved.

Both MAPKs and NF- $\kappa$ B play key roles in the regulation of transcriptional activity of pro-inflammatory genes in microglia (Kim and Choi, 2010; Bachstetter et al., 2011; KopitarJerala, 2015; Shih et al., 2015). The major MAPK pathway subfamilies involved in the regulation of cytokines in LPSactivated microglia include signaling proteins such as p38 MAPK, extracellular signal-regulated kinase (ERK1/2), and
c-jun-N terminal kinase (JNK), and NF- $\kappa$ B (Singh et al., 2014; Kumar et al., 2015; Velagapudi et al., 2017). p38 MAPK is involved in the ATP-induced MP shedding and cytokine release in glial cultures (Bianco et al., 2009) and has been shown to act as an upstream regulator of nSMase2 (Clarke et al., 2007; Filosto et al., 2010). Here, altenusin treatment significantly reduced LPS-induced phosphorylation of p38 and ERK1/2 but had no effect on JNK phosphorylation. Stimulation of microglia with LPS also leads to $\mathrm{I} \kappa \mathrm{B}$ degradation, facilitating the translocation of NF- $\kappa \mathrm{B}$ to the nucleus and subsequent transcription of proinflammatory cytokines (Olajide et al., 2014). In contrast to p38/ERK MAPK, we did not observe any significant changes in the levels of $\mathrm{I}_{\kappa} \mathrm{B} \alpha$ following altenusin treatment, suggesting that the antiinflammatory effects may involve attenuation of nSMasesdependent activation of specific pro-inflammatory MAPK pathways. Our data indicate that the anti-inflammatory effects exerted by altenusin may involve p38 and ERK1/2 signaling pathways, but not the JNK and NF- $\kappa$ B pathways.

A major driver of the neurotoxic microglial activation phenotype is NADPH oxidase (NOX2), an enzyme system highly expressed on phagocytes that produces reactive oxygen species and regulates pro-inflammatory activation pathways through NF- $\kappa$ B-dependent pathways (Gao et al., 2012). In prior studies, we demonstrated that TBI upregulated NADPH oxidase subunits $\mathrm{p} 22^{\text {phox }}$ and NOX2 in reactive microglia in the injured cortex and that NOX2 was highly expressed in CD68/Iba1-positive microglia at 1 year postinjury (Loane et al., 2014). Furthermore, NOX2 deficiency reduces proinflammatory activation of microglia following TBI (Kumar et al., 2016). These findings indicate that NOX2 contributes to pro-inflammatory microglial activation and release of neurotoxic mediators following TBI. In the current study we 
A

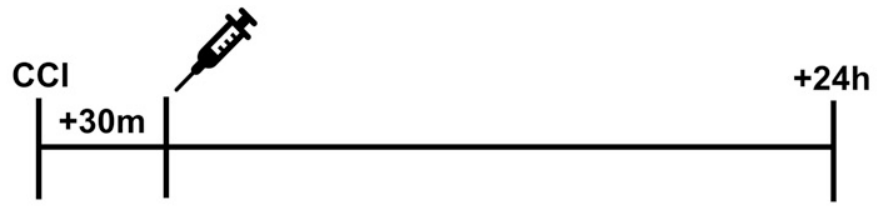

i.p. injection

Altenusin: $2 \mathrm{mg} / \mathrm{kg} \& 10 \mathrm{mg} / \mathrm{kg}$

Vehicle

\section{Perfusion and \\ Tissue collection}
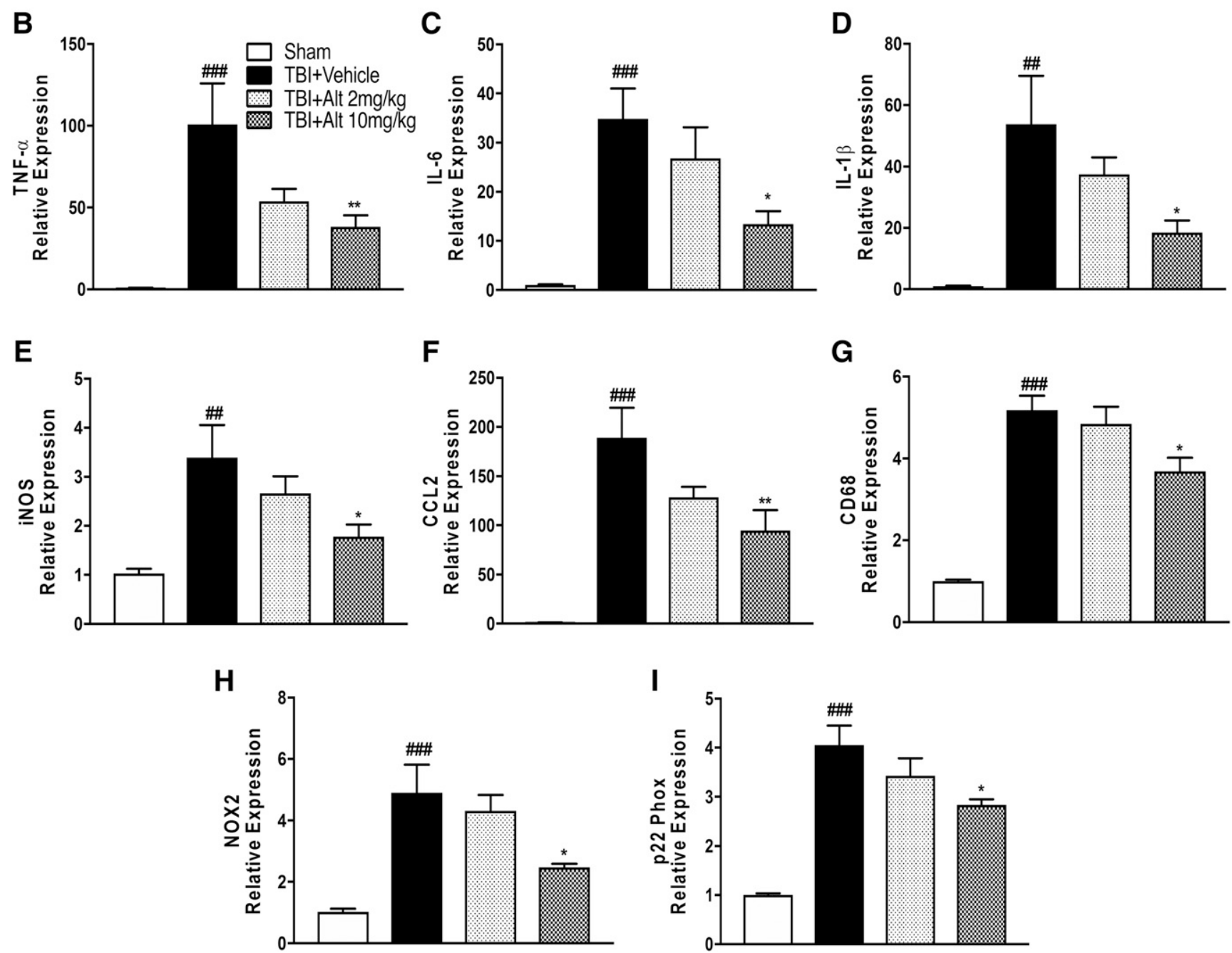

Fig. 8. Systemic administration of altenusin $(2$ and $10 \mathrm{mg} / \mathrm{kg})$ at 30 minutes postinjury. Mice were euthanized and perfused after 24 hours, and cortical tissue was processed for mRNA analysis (A). Gene expression of proinflammatory molecules were analyzed in the cortex of sham, vehicle, and altenusin administered TBI mice (vehicle-treated CCI significantly induced expression of proinflammatory mediators, TNF- $\alpha$ (B), IL-6 (C), IL-1 $\beta$ (D), iNOS (E) CCL2 (F), and microglia activation marker CD68 (G), reactive oxygen species (ROS) inducer NOX2 (H) and p22-phox (I), compared with sham-treated animals. Altenusin treatment $(10 \mathrm{mg} / \mathrm{kg})$ significantly reduced expression of all above mentioned genes. Analysis done by one-way ANOVA, followed by post hoc adjustments using Tukey's multiple comparison test. Results are expressed as means \pm S.E.M. $(N=5-7$ animals each group). $* P<0.05$, ${ }_{* *} P<0.01$ in comparison with TBI (vehicle); ${ }^{\# \#} P<0.01$, \#\#\# $P<0.001$ in comparison with sham.

demonstrate the effect of nSMase inhibition on the expression of NADPH oxidase subunit gene expression (NOX2, p22 $\left.2^{\text {phox }}\right)$ and pro-inflammatory gene expression following TBI, indicating that this important neurotoxic microglial activation pathway is inhibited by nSMase inhibitors. Notably, systemic administration of altenusin immediately following TBI significantly decreased the expression of proinflammatory and reactive microglial markers TNF $\alpha$, IL-6, IL-1 $\beta$, iNOS, CCL2, CD68, NOX2, and $2^{22^{\text {phox }}}$ in the injured cortex of mice.
Microglia are not only pro-inflammatory or neurotoxic but also produce anti-inflammatory cytokines, alternative activation markers, and neurotrophic factors that can have positive and beneficial functions in resolving inflammation (Loane and Kumar, 2016). To address the effect of effects of altenusin on these programs, we examined the gene expression of antiinflammatory cytokines and alternative activation markers (IL-10, IL-4ra, Arg-1, Mrc1, and Ym1) in the injured cortex at 24 hours postinjury. Our results indicate that altenusin reduces pro-inflammatory responses in the injured brain 

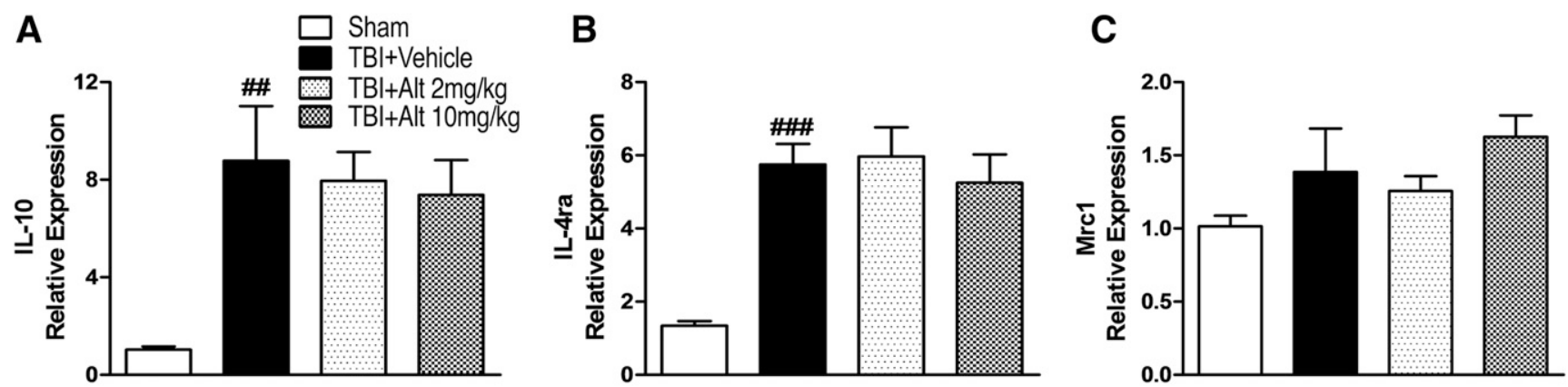

D

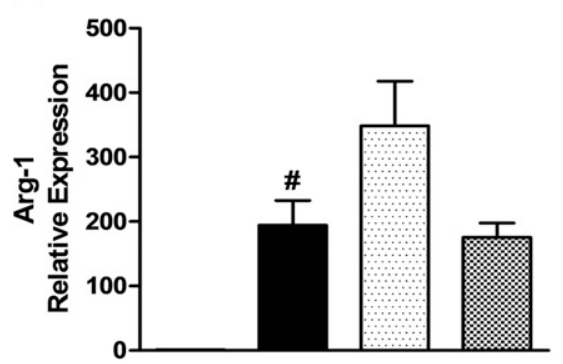

E

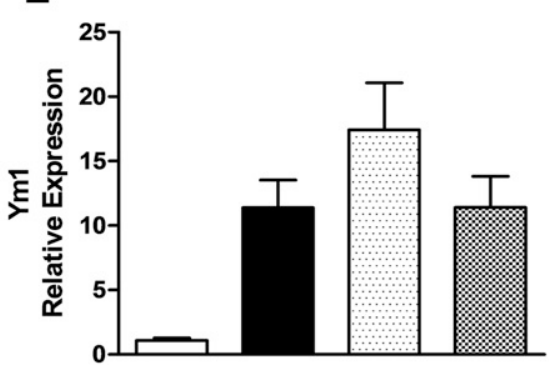

Fig. 9. Systemic administration of altenusin $(2$ and $10 \mathrm{mg} / \mathrm{kg})$ at 30 minutes postinjury. Mice were euthanized and perfused after $24 \mathrm{hours}$, and cortical tissue was processed for mRNA analyses. Gene expression of anti-inflammatory and alternative activation markers IL-10 (A), IL-4ra (B), Mrc1/CD206 (C), Arg-1 (D), and Ym1/Chil3 (E) were analyzed in the cortex of sham, vehicle, and altenusin administered TBI mice. Analysis done by one-way ANOVA, followed by post hoc adjustments using Tukey's multiple comparison test. Results are expressed as means \pm S.E.M. ( $N=4-7$ animals each group). ${ }^{\#} P<0.05,{ }^{\# \#} P<0.01,{ }^{\# \# \# P}<0.001$ in comparison with sham treatment.

without upregulating anti-inflammatory and alternative activation pathways. Given altenusin's ability to attenuate early inflammatory events, it may be effective in improving longterm neurobehavioral and neuropathological outcomes after TBI. A challenge for the therapeutic application of nSMase inhibitors is that inhibition of nSMase 2 may cause memory impairment (Tabatadze et al., 2010) and motor deficits (Tan et al., 2018). However, when examined in the context of AD-associated pathology, genetic nSMase2 deficiency improved cognition (Dinkins et al., 2016), suggesting that in conditions where nSMases play a key role for the development of the pathologic process, their inhibition may, on balance, have significant therapeutic value.

Together, our studies underscore the anti-inflammatory effects of selective nSMase inhibition following experimental TBI and their potential as therapeutic target after head injury. Further investigation is warranted to elucidate the effects of nSMase inhibitors, particularly altenusin, on behavioral outcomes following brain trauma.

\section{Acknowledgments}

We thank Ming Yang, Victoria Meadows, and Niaz Khan for their excellent technical assistance. We are grateful to Stephen R. Thom (University of Maryland Baltimore) for providing us the access to use flow cytometer instrument.

\section{Authorship Contributions}

Participated in research design: Kumar, Stoica, Loane.

Conducted experiments: Kumar, Henry, Abulwerdi, Bhat.

Performed data analysis: Kumar.

Wrote or contributed to the writing of the manuscript: Kumar, Stoica, Loane, Faden.

\section{References}

Aly AH, Edrada-Ebel R, Indriani ID, Wray V, Müller WEG, Totzke F, Zirrgiebel U, Schächtele C, Kubbutat MHG, Lin WH, et al. (2008) Cytotoxic metabolites from the fungal endophyte Alternaria sp. and their subsequent detection in its host plant Polygonum senegalense. J Nat Prod 71:972-980.

Bachstetter AD, Xing B, de Almeida L, Dimayuga ER, Watterson DM, and Van Eldik LJ (2011) Microglial p38 $\alpha$ MAPK is a key regulator of proinflammatory cytokine up-regulation induced by toll-like receptor (TLR) ligands or beta-amyloid (A $\beta$ ). $J$ Neuroinflammation 8:79.

Balusu S, Van Wonterghem E, De Rycke R, Raemdonck K, Stremersch S, Gevaert K, Brkic M, Demeestere D, Vanhooren V, Hendrix A, et al. (2016) Identification of a novel mechanism of blood-brain communication during peripheral inflammation via choroid plexus-derived extracellular vesicles. EMBO Mol Med 8:1162-1183.

Beneventano M, Spampinato SF, Merlo S, Chisari M, Platania P, Ragusa M, Purrello M, Nicoletti F, and Sortino MA (2017) Shedding of microvesicles from microglia contributes to the effects induced by metabotropic glutamate receptor 5 activation on neuronal death. Front Pharmacol 8:812.

Bianco F, Perrotta C, Novellino L, Francolini M, Riganti L, Menna E, Saglietti L, Schuchman EH, Furlan R, Clementi E, et al. (2009) Acid sphingomyelinase activity triggers microparticle release from glial cells. EMBO J 28:1043-1054.

Bianco F, Pravettoni E, Colombo A, Schenk U, Möller T, Matteoli M, and Verderio C (2005) Astrocyte-derived ATP induces vesicle shedding and IL-1 beta release from microglia. J Immunol 174:7268-7277.

Bilousova T, Elias C, Miyoshi E, Alam MP, Zhu C, Campagna J, Vadivel K, Jagodzinska B, Gylys KH, and John V (2018) Suppression of tau propagation using an inhibitor that targets the DK-switch of nSMase2. Biochem Biophys Res Commun 499:751-757.

Bohman L-E, Riley J, Milovanova TN, Sanborn MR, Thom SR, and Armstead WM (2016) Microparticles impair hypotensive cerebrovasodilation and cause hippocampal neuronal cell injury after traumatic brain injury. $J$ Neurotrauma 33: 168-174.

Brann AB, Tcherpakov M, Williams IM, Futerman AH, and Fainzilber M (2002) Nerve growth factor-induced p75-mediated death of cultured hippocampal neurons is age-dependent and transduced through ceramide generated by neutral sphingomyelinase. J Biol Chem 277:9812-9818.

Brites D and Fernandes A (2015) Neuroinflammation and depression: microglia activation, extracellular microvesicles and microRNA dysregulation. Front Cell Neurosci 9:476.

Butovsky O, Jedrychowski MP, Cialic R, Krasemann S, Murugaiyan G, Fanek Z, Greco DJ, Wu PM, Doykan CE, Kiner O, et al. (2015) Targeting miR-155 restores abnormal microglia and attenuates disease in SOD1 mice. Ann Neurol 77:75-99.

Byrnes KR, Loane DJ, Stoica BA, Zhang J, and Faden AI (2012) Delayed mGluR5 activation limits neuroinflammation and neurodegeneration after traumatic brain injury. J Neuroinflammation 9:43. 
Caballero-Garrido E, Pena-Philippides JC, Lordkipanidze T, Bragin D, Yang Y, Erhardt EB, and Roitbak T (2015) In vivo inhibition of mir-155 promotes recovery after experimental mouse stroke. J Neurosci 35:12446-12464.

Cardoso AL, Guedes JR, Pereira de Almeida L, and Pedroso de Lima MC (2012) miR155 modulates microglia-mediated immune response by down-regulating SOCS-1 and promoting cytokine and nitric oxide production. Immunology 135:73-88.

Chua SW, Cornejo A, van Eersel J, Stevens CH, Vaca I, Cueto M, Kassiou M, Gladbach A, Macmillan A, Lewis L, et al. (2017) The polyphenol altenusin inhibits in vitro fibrillization of tau and reduces induced tau pathology in primary neurons. ACS Chem Neurosci 8:743-751.

Clarke CJ, Cloessner EA, Roddy PL, and Hannun YA (2011) Neutral sphingomyelinase 2 (nSMase2) is the primary neutral sphingomyelinase isoform activated by tumour necrosis factor- $\alpha$ in MCF-7 cells. Biochem J 435:381-390.

Clarke CJ, Truong T-G, and Hannun YA (2007) Role for neutral sphingomyelinase-2 in tumor necrosis factor $\alpha$-stimulated expression of vascular cell adhesion molecule-1 (VCAM) and intercellular adhesion molecule-1 (ICAM) in lung epithelial cells: p38 MAPK is an upstream regulator of nSMase2. J Biol Chem 282: 1384-1396.

Dickens AM, Tovar-Y-Romo LB, Yoo SW, Trout AL, Bae M, Kanmogne M, Megra B, Williams DW, Witwer KW, Gacias M, et al. (2017) Astrocyte-shed extracellular vesicles regulate the peripheral leukocyte response to inflammatory brain lesions. Sci Signal 10.

Dinkins MB, Enasko J, Hernandez C, Wang G, Kong J, Helwa I, Liu Y, Terry AV Jr, and Bieberich E (2016) Neutral sphingomyelinase-2 deficiency ameliorates Alzheimer's disease pathology and improves cognition in the 5XFAD mouse. $J$ Neurosci 36:8653-8667.

Essandoh K, Yang L, Wang X, Huang W, Qin D, Hao J, Wang Y, Zingarelli B, Peng T, and Fan G-C (2015) Blockade of exosome generation with GW4869 dampens the sepsis-induced inflammation and cardiac dysfunction. Biochim Biophys Acta 1852. $2362-2371$.

Fenn AM, Gensel JC, Huang Y, Popovich PG, Lifshitz J, and Godbout JP (2014) Immune activation promotes depression 1 month after diffuse brain injury: a role for primed microglia. Biol Psychiatry 76:575-584.

Figuera-Losada M, Stathis M, Dorskind JM, Thomas AG, Bandaru VVR, Yoo S-W, Westwood NJ, Rogers GW, McArthur JC, Haughey NJ, et al. (2015) Cambinol, a novel inhibitor of neutral sphingomyelinase 2 shows neuroprotective properties. PLoS One 10:e124481.

Filosto S, Fry W, Knowlton AA, and Goldkorn T (2010) Neutral sphingomyelinase 2 (nSMase2) is a phosphoprotein regulated by calcineurin (PP2B). J Biol Chem 285:10213-10222.

Fu R, Shen Q, Xu P, Luo JJ, and Tang Y (2014) Phagocytosis of microglia in the central nervous system diseases. Mol Neurobiol 49:1422-1434.

Gao H-M, Zhou H, and Hong J-S (2012) NADPH oxidases: novel therapeutic targets for neurodegenerative diseases. Trends Pharmacol Sci 33:295-303.

Gao W, Liu H, Yuan J, Wu C, Huang D, Ma Y, Zhu J, Ma L, Guo J, Shi H, et al. (2016) Exosomes derived from mature dendritic cells increase endothelial inflammation and atherosclerosis via membrane TNF- $\alpha$ mediated NF-kB pathway. J Cell Mol Med 20:2318-2327.

Gu L, Huang B, Shen W, Gao L, Ding Z, Wu H, and Guo J (2013) Early activation of nSMase2/ceramide pathway in astrocytes is involved in ischemia-associated neuronal damage via inflammation in rat hippocampi. $J$ Neuroinflammation 10:109.

Guedes J, Cardoso ALC, and Pedroso de Lima MC (2013) Involvement of microRNA in microglia-mediated immune response. Clin Dev Immunol 2013:186872.

Guedes JR, Custódia CM, Silva RJ, de Almeida LP, Pedroso de Lima MC, and Cardoso AL (2014) Early miR-155 upregulation contributes to neuroinflammation in Alzheimer's disease triple transgenic mouse model. Hum $\mathrm{Mol}$ Genet 23:6286-6301.

Guo BB, Bellingham SA, and Hill AF (2015) The neutral sphingomyelinase pathway regulates packaging of the prion protein into exosomes. $J$ Biol Chem 290 $3455-3467$.

Hanisch U-K (2002) Microglia as a source and target of cytokines. Glia 40:140-155

Harrison EB, Emanuel K, Lamberty BG, Morsey BM, Li M, Kelso ML, Yelamanchili SV, and Fox HS (2017) Induction of mir-155 after brain injury promotes type 1 interferon and has a neuroprotective effect. Front Mol Neurosci 10:228.

Harrison EB, Hochfelder CG, Lamberty BG, Meays BM, Morsey BM, Kelso ML, Fox HS, and Yelamanchili SV (2016) Traumatic brain injury increases levels of miR-21 in extracellular vesicles: implications for neuroinflammation. FEBS Open Bio 6 $835-846$.

Harrison-Brown M, Liu G-J, and Banati R (2016) Checkpoints to the brain: directing myeloid cell migration to the central nervous system. Int J Mol Sci 17.

Hazelton I, Yates A, Dale A, Roodselaar J, Akbar N, Ruitenberg MJ, Anthony DC, and Couch Y (2018) Exacerbation of acute traumatic brain injury by circulating extracellular vesicles. J Neurotrauma 35:639-651.

Henry RJ, Doran SJ, Barrett JP, Meadows VE, Sabirzhanov B, Stoica BA, Loane DJ, and Faden AI (2018) Inhibition of mir-155 limits neuroinflammation and improves functional recovery after experimental traumatic brain injury in mice. Neurotherapeutics DOI: 10.1007/s13311-018-0665-9 [published ahead of print].

Hide I, Tanaka M, Inoue A, Nakajima K, Kohsaka S, Inoue K, and Nakata Y (2000) Extracellular ATP triggers tumor necrosis factor-alpha release from rat microglia. $J$ Neurochem 75:965-972.

Huang Y, Li Y, Zhang H, Zhao R, Jing R, Xu Y, He M, Peer J, Kim YC, Luo J, et al. (2018) Zika virus propagation and release in human fetal astrocytes can be suppressed by neutral sphingomyelinase-2 inhibitor GW4869. Cell Discov 4: 19

Hulsmans M and Holvoet P (2013) MicroRNA-containing microvesicles regulating inflammation in association with atherosclerotic disease. Cardiovasc Res 100:7-18.

Hung T-H, Shyue S-K, Wu C-H, Chen C-C, Lin C-C, Chang C-F, and Chen S-F (2017) Deletion or inhibition of soluble epoxide hydrolase protects against brain damage and reduces microglia-mediated neuroinflammation in traumatic brain injury. Oncotarget 8:103236-103260.
Iguchi Y, Eid L, Parent M, Soucy G, Bareil C, Riku Y, Kawai K, Takagi S, Yoshida M, Katsuno M, et al. (2016) Exosome secretion is a key pathway for clearance of pathological TDP-43. Brain 139:3187-3201.

Jayadev S, Case A, Alajajian B, Eastman AJ, Möller T, and Garden GA (2013) Presenilin 2 influences miR146 level and activity in microglia. J Neurochem 127: 592-599.

Kabadi SV, Stoica BA, Hanscom M, Loane DJ, Kharebava G, Murray Ii MG, Cabatbat RM, and Faden AI (2012) CR8, a selective and potent CDK inhibitor, provides neuroprotection in experimental traumatic brain injury. Neurotherapeutics $\mathbf{9}$ $405-421$.

Kaminska B (2005) MAPK signalling pathways as molecular targets for antiinflammatory therapy--from molecular mechanisms to therapeutic benefits. Biochim Biophys Acta 1754:253-262.

Kaminska B, Gozdz A, Zawadzka M, Ellert-Miklaszewska A, and Lipko M (2009) MAPK signal transduction underlying brain inflammation and gliosis as therapeutic target. Anat Rec (Hoboken) 292:1902-1913.

Kim EK and Choi E-J (2010) Pathological roles of MAPK signaling pathways in human diseases. Biochim et Biophys Acta 1802:396-405.

Kopitar-Jerala N (2015) Innate immune response in brain, NF-kappa B signaling and cystatins. Front Mol Neurosci 8:73.

Kumar A, Alvarez-Croda D-M, Stoica BA, Faden AI, and Loane DJ (2016a) Microglial/Macrophage polarization dynamics following traumatic brain injury. $J$ Neurotrauma 33:1732-1750.

Kumar A, Barrett JP, Alvarez-Croda D-M, Stoica BA, Faden AI, and Loane DJ (2016b) NOX2 drives M1-like microglial/macrophage activation and neurodegeneration following experimental traumatic brain injury. Brain Behav Immun 58:291-309.

Kumar A, Bhatia HS, de Oliveira ACP, and Fiebich BL (2015) microRNA-26a modulates inflammatory response induced by toll-like receptor 4 stimulation in microglia. J Neurochem 135:1189-1202.

Kumar A, Stoica BA, Loane DJ, Yang M, Abulwerdi G, Khan N, Kumar A, Thom SR, and Faden AI (2017) Microglial-derived microparticles mediate neuroinflammation after traumatic brain injury. $J$ Neuroinflammation 14:47.

Lee J-T, Xu J, Lee J-M, Ku G, Han X, Yang D-I, Chen S, and Hsu CY (2004) Amyloidbeta peptide induces oligodendrocyte death by activating the neutral sphingomyelinase-ceramide pathway. J Cell Biol 164:123-131.

Li J, Li X, Jiang X, Yang M, Yang R, Burnstock G, Xiang Z, and Yuan H (2017) Microvesicles shed from microglia activated by the P2X7-p38 pathway are involved in neuropathic pain induced by spinal nerve ligation in rats. Purinergic Signal 13 $13-26$.

Livak KJ and Schmittgen TD (2001) Analysis of relative gene expression data using real-time quantitative PCR and the 2(- $\Delta \mathrm{C}(\mathrm{T}))$ Method. Methods 25:402-408.

Loane DJ and Byrnes KR (2010) Role of microglia in neurotrauma. Neurotherapeutics 7:366-377

Loane DJ and Kumar A (2016) Microglia in the TBI brain: the good, the bad, and the dysregulated. Exp Neurol 275:316-327.

Loane DJ, Kumar A, Stoica BA, Cabatbat R, and Faden AI (2014a) Progressive neurodegeneration after experimental brain trauma: association with chronic microglial activation. J Neuropathol Exp Neurol 73:14-29.

Loane DJ, Stoica BA, Byrnes KR, Jeong W, and Faden AI (2013) Activation of mGluR5 and inhibition of NADPH oxidase improves functional recovery after traumatic brain injury. J Neurotrauma 30:403-412.

Loane DJ, Stoica BA, Pajoohesh-Ganji A, Byrnes KR, and Faden AI (2009) Activation of metabotropic glutamate receptor 5 modulates microglial reactivity and neurotoxicity by inhibiting NADPH oxidase. J Biol Chem 284:15629-15639.

Loane DJ, Stoica BA, Tchantchou F, Kumar A, Barrett JP, Akintola T, Xue F, Conn PJ, and Faden AI (2014b) Novel mGluR5 positive allosteric modulator improves functional recovery, attenuates neurodegeneration, and alters microglial polarization after experimental traumatic brain injury. Neurotherapeutics 11:857-869.

Luberto C, Hassler DF, Signorelli P, Okamoto Y, Sawai H, Boros E, Hazen-Martin DJ, Obeid LM, Hannun YA, and Smith GK (2002) Inhibition of tumor necrosis factor-induced cell death in MCF7 by a novel inhibitor of neutral sphingomyelinase. $J$ Biol Chem 277:41128-41139.

Mao S-S, Hua R, Zhao X-P, Qin X, Sun Z-Q, Zhang Y, Wu Y-Q, Jia M-X, Cao J-L, and Zhang Y-M (2012) Exogenous administration of PACAP alleviates traumatic brain injury in rats through a mechanism involving the TLR4/MyD88/NF-kB pathway. J Neurotrauma 29:1941-1959.

Martinez TN, Chen X, Bandyopadhyay S, Merrill AH, and Tansey MG (2012) Ceramide sphingolipid signaling mediates Tumor Necrosis Factor (TNF)-dependent toxicity via caspase signaling in dopaminergic neurons. Mol Neurodegener 7:45.

Menck K, Sönmezer C, Worst TS, Schulz M, Dihazi GH, Streit F, Erdmann G, Kling S, Boutros M, Binder C, et al. (2017) Neutral sphingomyelinases control extracellular vesicles budding from the plasma membrane. J Extracell Vesicles 6: 1378056 .

Montecalvo A, Larregina AT, Shufesky WJ, Stolz DB, Sullivan MLG, Karlsson JM, Baty CJ, Gibson GA, Erdos G, Wang Z, et al. (2012) Mechanism of transfer of functional microRNAs between mouse dendritic cells via exosomes. Blood 119 $756-766$.

Mosmann T (1983) Rapid colorimetric assay for cellular growth and survival: application to proliferation and cytotoxicity assays. J Immunol Methods 65:55-63.

Nigro A, Colombo F, Casella G, Finardi A, Verderio C, and Furlan R (2016) Myeloid extracellular vesicles: messengers from the demented brain. Front Immunol 7:17.

Novgorodov SA, Riley CL, Yu J, Borg KT, Hannun YA, Proia RL, Kindy MS, and Gudz TI (2014) Essential roles of neutral ceramidase and sphingosine in mitochondrial dysfunction due to traumatic brain injury. $J$ Biol Chem 289 13142-13154.

Olajide OA, Kumar A, Velagapudi R, Okorji UP, and Fiebich BL (2014) Punicalagin inhibits neuroinflammation in LPS-activated rat primary microglia. Mol Nutr Food Res 58:1843-1851. 
Paolicelli RC, Bergamini G, and Rajendran L (2018) Cell-to-cell communication by extracellular vesicles: focus on microglia. Neuroscience DOI: 10.1016/j.neuroscience.2018.04.003 [published ahead of print].

Pena-Philippides JC, Caballero-Garrido E, Lordkipanidze T, and Roitbak T (2016) In vivo inhibition of miR-155 significantly alters post-stroke inflammatory response. $J$ Neuroinflammation 13:287.

Perry VH, Nicoll JAR, and Holmes C (2010) Microglia in neurodegenerative disease. Nat Rev Neurol 6:193-201.

Pieragostino D, Cicalini I, Lanuti P, Ercolino E, di Ioia M, Zucchelli M, Zappacosta R, Miscia S, Marchisio M, Sacchetta P, et al. (2018) Enhanced release of acid sphingomyelinase-enriched exosomes generates a lipidomics signature in CSF of Multiple Sclerosis patients. Sci Rep 8:3071.

Poncelet P, Robert S, Bailly N, Garnache-Ottou F, Bouriche T, Devalet B, Segatchian JH, Saas P, and Mullier F (2015) Tips and tricks for flow cytometry-based analysis and counting of microparticles. Transfus Apher Sci 53:110-126.

Ponomarev ED, Veremeyko T, Barteneva N, Krichevsky AM, and Weiner HL (2011) MicroRNA-124 promotes microglia quiescence and suppresses EAE by deactivating macrophages via the C/EBP- $\alpha$-PU.1 pathway. Nat Med 17:64-70.

Prinz M and Priller J (2014) Microglia and brain macrophages in the molecular age from origin to neuropsychiatric disease. Nat Rev Neurosci 15:300-312.

Saba R, Gushue S, Huzarewich RLCH, Manguiat K, Medina S, Robertson C, and Booth SA (2012) MicroRNA 146a (miR-146a) is over-expressed during prion disease and modulates the innate immune response and the microglial activation state. PLoS One 7:e30832.

Saba R, Sorensen DL, and Booth SA (2014) MicroRNA-146a: a dominant, negative regulator of the innate immune response. Front Immunol 5:578.

Sabirzhanov B, Faden AI, Aubrecht T, Henry R, Glaser E, and Stoica BA (2018) MicroRNA-711-Induced downregulation of angiopoietin-1 mediates neuronal cell death. J Neurotrauma 35:2462-2481.

Sabirzhanov B, Zhao Z, Stoica BA, Loane DJ, Wu J, Borroto C, Dorsey SG, and Faden AI (2014) Downregulation of miR-23a and miR-27a following experimental traumatic brain injury induces neuronal cell death through activation of proapoptotic Bcl-2 proteins. $J$ Neurosci 34:10055-10071.

Shieh C-H, Heinrich A, Serchov T, van Calker D, and Biber K (2014) P2X7dependent, but differentially regulated release of IL-6, CCL2, and TNF- $\alpha$ in cultured mouse microglia. Glia 62:592-607.

Shih R-H, Wang C-Y, and Yang C-M (2015) NF-kappaB signaling pathways in neurological inflammation: a mini review. Front Mol Neurosci 8:77.

Singh V, Bhatia HS, Kumar A, de Oliveira ACP, and Fiebich BL (2014) Histone deacetylase inhibitors valproic acid and sodium butyrate enhance prostaglandins release in lipopolysaccharide-activated primary microglia. Neuroscience 265:147-157.

Sobue A, Ito N, Nagai T, Shan W, Hada K, Nakajima A, Murakami Y, Mouri A, Yamamoto Y, Nabeshima T, et al. (2018) Astroglial major histocompatibility complex class I following immune activation leads to behavioral and neuropathological changes. Glia 66:1034-1052.

Song L, Lee C, and Schindler C (2011) Deletion of the murine scavenger receptor CD68 J Lipid Res 52:1542-1550.

Stoica BA, Loane DJ, Zhao Z, Kabadi SV, Hanscom M, Byrnes KR, and Faden AI (2014) PARP-1 inhibition attenuates neuronal loss, microglia activation and neurological deficits after traumatic brain injury. J Neurotrauma 31:758-772.

Tabatadze N, Savonenko A, Song H, Bandaru VVR, Chu M, and Haughey NJ (2010) Inhibition of neutral sphingomyelinase-2 perturbs brain sphingolipid balance and spatial memory in mice. J Neurosci Res 88:2940-2951.

Tan LH-R, Tan AJ-R, Ng Y-Y, Chua JJ-E, Chew W-S, Muralidharan S, Torta F, Dutta B, Sze SK, Herr DR, et al. (2018) Enriched expression of neutral sphingomyelinase 2 in the striatum is essential for regulation of lipid raft content and motor coordination. Mol Neurobiol 55:5741-5756.

Taylor DD and Gercel-Taylor C (2014) Exosome platform for diagnosis and monitoring of traumatic brain injury. Philos Trans $R$ Soc Lond B Biol Sci $\mathbf{3 6 9}$.
Thelin EP, Tajsic T, Zeiler FA, Menon DK, Hutchinson PJA, Carpenter KLH, MorgantiKossmann MC, and Helmy A (2017) Monitoring the neuroinflammatory response following acute brain injury. Front Neurol 8:351.

Tian Y, Salsbery B, Wang M, Yuan H, Yang J, Zhao Z, Wu X, Zhang Y, Konkle BA, Thiagarajan P, et al. (2015) Brain-derived microparticles induce systemic coagulation in a murine model of traumatic brain injury. Blood 125:2151-2159.

Uchida R, Tomoda H, Dong Y, and Omura S (1999) Alutenusin, a specific neutral sphingomyelinase inhibitor, produced by Penicillium sp. FO-7436. J Antibiot (Tokyo) 52:572-574.

Velagapudi R, Kumar A, Bhatia HS, El-Bakoush A, Lepiarz I, Fiebich BL, and Olajide OA (2017) Inhibition of neuroinflammation by thymoquinone requires activation of Nrf2/ARE signalling. Int Immunopharmacol 48:17-29.

Walker DG and Lue L-F (2015) Immune phenotypes of microglia in human neurodegenerative disease: challenges to detecting microglial polarization in human brains. Alzheimers Res Ther 7:56.

Woodcock T and Morganti-Kossmann MC (2013) The role of markers of inflammation in traumatic brain injury. Front Neurol 4:18

Wu BX, Rajagopalan V, Roddy PL, Clarke CJ, and Hannun YA (2010) Identification and characterization of murine mitochondria-associated neutral sphingomyelinase (MA-nSMase), the mammalian sphingomyelin phosphodiesterase 5. J Biol Chem 285:17993-18002.

Wu M, Harvey KA, Ruzmetov N, Welch ZR, Sech L, Jackson K, Stillwell W, Zaloga GP, and Siddiqui RA (2005) Omega-3 polyunsaturated fatty acids attenuate breast cancer growth through activation of a neutral sphingomyelinase-mediated pathway. Int $J$ Cancer 117:340-348.

Xiao C, Wang K, Xu Y, Hu H, Zhang N, Wang Y, Zhong Z, Zhao J, Li Q, Zhu D, et al. (2018) Transplanted mesenchymal stem cells reduce autophagic flux in infarcted hearts via the exosomal transfer of mir-125b. Circ Res 123:564-578

Xiao T, Zhang W, Jiao B, Pan C-Z, Liu X, and Shen L (2017) The role of exosomes in the pathogenesis of Alzheimer' disease. Transl Neurodegener 6:3.

Yang Y, Boza-Serrano A, Dunning CJR, Clausen BH, Lambertsen KL, and Deierborg $\mathrm{T}$ (2018) Inflammation leads to distinct populations of extracellular vesicles from microglia. $J$ Neuroinflammation 15:168.

Yin H, Song S, and Pan X (2017) Knockdown of miR-155 protects microglia against LPS-induced inflammatory injury via targeting RACK1: a novel research for intracranial infection. J Inflamm (Lond) 14:17.

Yuan Y, Zhu F, Pu Y, Wang D, Huang A, Hu X, Qin S, Sun X, Su Z, and He C (2015 Neuroprotective effects of nitidine against traumatic CNS injury via inhibiting microglia activation. Brain Behav Immun 48:287-300.

Zeng C, Lee JT, Chen H, Chen S, Hsu CY, and Xu J (2005) Amyloid-beta peptide enhances tumor necrosis factor-alpha-induced iNOS through neutral sphingomyelinase/ceramide pathway in oligodendrocytes. J Neurochem 94:703-712.

Zhao L, Luo H, Li X, Li T, He J, Qi Q, Liu Y, and Yu Z (2017) Exosomes derived from human pulmonary artery endothelial cells shift the balance between proliferation and apoptosis of smooth muscle cells. Cardiology 137:43-53.

Zheng Z, Zhao Z, Li S, Lu X, Jiang M, Lin J, An Y, Xie Y, Xu M, Shen W, et al. (2017) Altenusin, a nonsteroidal microbial metabolite, attenuates nonalcoholic fatty liver disease by activating the farnesoid X receptor. Mol Pharmacol 92 425-436.

Address correspondence to: Dr. Alan I. Faden, Departments of Anesthesiology, Anatomy and Neurobiology, Neurosurgery, and Neurology, and Center for Shock, Trauma and Anesthesiology Research (STAR), University of Maryland School of Medicine, Baltimore, MD 21201. E-mail: afaden1@som. umaryland.edu; or Dr. Asit Kumar, Department of Anesthesiology and Shock, Trauma and Anesthesiology Research (STAR) Center, University of Maryland School of Medicine, Baltimore, MD 21201. E-mail: asitkumar14@gmail.com 